\title{
Shipping Optimisation Systems (SOS): tramp optimisation perspective
}

\author{
Said El Noshokaty
}

\section{Correspondence:}

selnoshokaty@elesteshary.com El Esteshary Information Systems (EIS), 637 Horreya Avenue, Genaklis, Alexandria 21411, Egypt

\section{Introduction}

If compared to other businesses, cargo transportation in tramp mode has three distinctive characteristics. The first characteristic is that its production cycle (ship voyage) passes through different economic systems which cause uncertainty and create unstructured decision situation (Fields and Shingles 2016). In an unstructured decision

(c) The Author(s). 2017 Open Access This article is distributed under the terms of the Creative Commons Attribution 4.0 International License (http://creativecommons.org/licenses/by/4.0/), which permits unrestricted use, distribution, and reproduction in any medium, provided you give appropriate credit to the original author(s) and the source, provide a link to the Creative Commons license, and indicate if changes were made.
Keywords: Optimal cargo mix, Transportation scheduling, Transportation routing,

Transportation allocation, Transportation appraisal

\begin{abstract}
This research paper is to announce a new policy to all systems which are sensitive to each ship the cargo mix which contributes more to a gross-profit objective, assuming deterministic cargo transport demand. Since tramp cargo transportation is sensitive to where time varies considerably from one alternative ship voyage to another. The assuming both deterministic and stochastic cargo transport demand. To introduce this SOS selects the most profitable cargo mix. This mix is selected because of the higher voyage, created by the system, to allocate fleet units to cargo trade areas, specifying fleet allocation is that the allocated frequency of calls may be considered as representing the demand on services of utilities of ports, canals, and straits, and may be sensitivity and what-if analysis, can determine whether calling at a utility of a trade area is sensitive to changes made to utility dues and staying time, cargo quantities and For appraising purposes, SOS includes new ships in the allocation process, in ship, along with other cash flow and cost of investment. SOS similar systems may be shortest possible transportation time owners of transport units can afford. Case studies are brought to demonstrate research findings.
\end{abstract}


situation, solution steps are usually not known beforehand. The second characteristic is that production time (voyage time) varies considerably from one alternative production cycle to another. The production cycle is said to be time-sensitive because of this variation in time. The variation is mainly caused by the alternative cargo mixes available for transport in competition with other ships, the alternative shipping routes the ship may follow towards the same cargo mix, and the alternative ship speeds at which the ship may sail. In comparison, the production cycle in liner shipping is not sensitive to time since production time is fixed where the ship sails per a predetermined itinerary (see El Noshokaty 2013). Likewise, crop harvesting in agriculture, car manufacturing and assembly lines in industry, and road paving in construction are all not timesensitive. Time-sensitivity is known to the ship owner when he hires his ship as a time charter for a better hire per-day, main while he ignores it when he does not hire his ship as a voyage charter for a better gross profit per day (Time Charter Equivalent rate in voyage charter is not the gross profit per day as been defined in this paper). However, the ship owner shows awareness of time sensitivity when he puts in the voyage charter party a clause specifying a minimum cargo loading and discharging rate. His intention is to minimise voyage time. This action influences few cost and revenue items plus cargo handling days, while a gross-profit-per-day objective influences all cost and revenue items plus all voyage days, including sailing and waiting days. The gross-profitper-day objective is more described hereinafter. The third characteristic is that transportation unit calls at a variable number of stops and follows many calling sequences among these stops. In other words, a transportation unit does not operate on a published schedule but serves different stops in response to tenders of cargo. It runs like a taxi cab in private transport if compared to a bus in public transport. This mode of operation requires, in model terminology, many variables and constraints which in turn requires the use of mathematical models (Christiansen and Fagerholt 2014).

If one thinks of a solution methodology to solve tramp transportation problems, he must overcome three main problems; one for each business characteristic mentioned earlier. The first problem is the uncertainty or randomness in factors affecting the business. There should be a stochastic formulation by which one can explore future cargo transport demand. Knowing this demand will help owners of transportation units making more sound unstructured operational decisions. It might be better to consider a cargo expected to be offered more than a one that is offered if the former will most likely contribute more towards gross profit (the term 'offered' refers to a confirmed shipping proposal, while 'not-yet-offered' refers to an unconfirmed or expected shipping proposal). The second problem is the use of a gross-profit-per-day objective, rather than a gross-profit one; since time varies considerably from one alternative ship voyage to another. Gross-profit-per-day objective cares for the higher gross profit it yields and the less number of days it takes to generate such profit. To explain, assume there are two cargoes and one must choose only one: cargo A which yields a gross profit of \$ 2 million in 200 days ( $\$ 10,000$ per day), and cargo B which yields a gross profit of \$ 1.5 million in 100 days (\$15,000 per day). Although cargo B generates less gross profit, it causes the transport-unit owner to get $\$ 3$ million in 200 days instead of $\$ 2$ million, if the owner highly expects that shippers will offer B-like cargo after the 100 days. To account for such expectation, the gross-profit-per-day objective must have a stochastic formulation to incorporate future transport demand as what has been 
mentioned earlier. In contrast, the current practice of ship owners is to choose cargo A with a Time Charter Eqivalent rate of $\$ 10,000$. The third problem is the need to explore massive alternative solutions before reaching the optimal solution. Fortunately, Operations Research (OR) techniques provide such solution methodology. The impact of the optimal solution provided by OR on any logistics and supply chain system is that it maintains the shortest possible transportation time owners of transport units can afford. The challenge in using OR models is in including all the necessary parameters and business rules that represent a real cargo transport problem. And, because some of these parameters are fixed, they need to be checked for validity. Also, OR models have to be incorporated within a decision support system in order to allow non-OR users to deliver model parameters, and to run and interact with these models.

The above-mentioned introduction lays the ground needed to understand the contribution of this paper if compared to other papers in the current cargo transportation literature. Current research papers are used to select the cargo mix based on the contribution it adds to the gross-profit of each transport unit, assuming deterministic transport demand for each cargo (gross profit per day and randomness of cargo demand are two important issues in tramp shipping not to ignore). The models in such papers do not present real shipping elements and rules (20 such elements and rules, all affect profitability, are discussed in SOS Voyager Optimisation Model). If these research papers use OR-based models, users of these models must acquire additional skills related to OR (in contrast, decision support systems have OR models built-in). Finally, current research papers usually do not check for validity of model parameters, especially cargo quantity and freight, cargo handling rate and charges, and ship speed and fuel consumption (sensitivity and what-if analysis, which are usually used to check such validity, do not appear in any of these research papers). A research question which could be raised at this point is: Is there any way to avoid these comments on current research papers? The answer which is yes is given by this research paper. It has the following research purpose. It is to use the ship in tramp mode, as an example, to show how a cargo transportation unit can use OR models with a stochastic gross-profit-per-day objective to select the cargo mix that improves profitability and enhance any logistics and supply chain system the ship is part of. Decision support systems (DSS), which are developed to serve this purpose, are called Shipping Optimisation Systems (SOS). SOS contains realistic shipping elements and rules and can check the validity of these elements and rules. An added purpose of this research paper is to use the optimal gross profit which can be generated by SOS for each ship voyage completed on each trade area to allocate the fleet units to trade areas, with a specified calling frequency for each unit on each trade area. While the former purpose cares for the alternative production cycles caused by the alternative cargo mixes ready to be transported within a short-term planning period, the added purpose cares for the alternative production cycles caused by the alternative trade areas ready to be serviced within a long-term planning period. Each trade area has its own characteristics of commodity type, quantity and freight of cargo, service cost, and sailing distance. One useful application of this allocation is to consider the frequency of calls as representing the demand on services rendered by utilities operating in each trade area. Another useful application is to include, in a competitive environment, 
the new ships along with the old ones in the allocation plan to find the share each new ship adds to total gross profit each year. SOS uses the new ship gross profit, along with other cash flow and cost of investment, to calculate the net present value of this new ship.

In the following section, current research papers are discussed to prove that the above-mentioned comments are true, and to see what possible contribution that could be made by this research paper to avoid these comments. A problem statement is formulated side by side along with the review of the literature.

\section{Problem statement and review of the literature in tramp shipping optimisation}

The term 'tramp shipping optimisation' refers to the use of OR to maximise the revenue or minimise the cost of a tramp shipping problem, subject to the limited shipping resources. One such tramp shipping problem exists when there are some ships and some cargoes and it is required to find out the cargo mix assigned to each ship voyage which maximises total gross profit per day for all ships, subject to ship capacity and cargo time window (lay can). Name this problem area 'optimisation of ship voyage'. To give more details on this area, consider the following facts. Unlike 'optimisation in liner shipping, both ports of call and port calling sequence are here assumed optional. Charter party, signed by the ship owner and the charterer, usually specifies terms and clauses to be followed by both parties. Non-demise voyage charter parties are assumed here. Terms generally include the following items: calling ports, calling sequence, cargo freight, cargo time window (lay can), allowable cargo handling time (lay days), dispatch count if actual days are less than lay days, and demurrage count if more. Loading and discharging lay days may be considered in reversible or irreversible manner. If reversible, lay days are specified for loading and discharging collectively. If irreversible, lay days are specified for loading and discharging separately. The gross terms of voyage charter party are here assumed unless otherwise specified. Before cargoes are being fixed by the ship owner, 'optimisation of ship voyage' helps in proposing a voyage plan suggesting an optimal cargo mix for each ship. This mix maximises the sum of voyage gross profit per day for all ships, subject to ship capacity, cargo lay can, and other voyage charter party terms. In the cargo mix selection, the random nature of sea transport demand has to be considered.

What is mentioned above describes the original problem in tramp shipping. In turning some or all the characteristics of 'optimisation of ship voyage' referred to in this problem into an OR model, the following research efforts were cited. A general review is given by Christiansen et al. (2004), Christiansen et al. (2013), and Christiansen and Fagerholt (2014). Appelgren $(1969,1971)$ addressed the problem of tramp shipping for a fleet of cargo ships. The problem of these research papers is to assign an optimal loading sequence of cargoes to each ship during a given time. Each cargo has a loading time window, size, type, port of loading, port of discharging, and cargo handling time in these ports. Each ship has its operational characteristics of the initial position, and expected daily marginal revenue of optional cargoes which may become available during the planning period. All contracted cargoes must be loaded, whereas optional cargoes may be accepted or rejected. A ship may carry only one cargo at a time. The objective is to maximise the revenue of optional cargoes minus cargo handling and fuel 
cost. The review of these research papers is reported in the follows items. The first is that their research model is most useful for bulk carriers since it assumes only one cargo to be loaded at a time. The second is that the problem known in the literature as the 'fixed-charge problem' is not addressed. In this problem, fixed charges; such as port dues, are to be paid no matter how many cargoes ship selects in each port. The third is that the objective does not consider the time taken to earn revenues. In tramp shipping, revenue or gross profit per day is a common objective.

Bauch et al. (1998) and Bremer and Perakis (1992a, 1992b) have put emphasis on application and implementation using an OR model not much different than that of Appelgren. The authors have captured raw data about cargoes, ships, ports, and distances and use it to generate all possible schedules for each ship. Each schedule identifies several cargoes to be transported, arranged and put in a predetermined sequence. Data pertaining to these schedules is input to an integer programming package as package parameters. The package was run to select the set of schedules that gives an optimal solution. The same review mentioned about Appelgren applies also here, plus the fact that the generation of all possible schedules is not guaranteed.

Fagerholt (2001) has developed an optimisation model for tramp shipping, where cargo time window (lay can) may be violated to a certain extent with a penalty cost in return. That is why cargo time window was given the name soft time window, and penalty cost was given the name inconvenience cost. The model designs a predetermined set of schedules for each ship to follow. In each schedule, there is a predetermined route with cargo pick-up and delivery nodes along with soft time window for each node and a predetermined ship speed on each sailing leg. The model objective is to find the schedule for each ship which minimises total operating and penalty cost. The review of this model is reported in the follows items. The first is that the number of schedules of each ship is too small to represent all candidate schedules. The second is that even if the number of schedules is large enough, the way the schedule is designed does not generate a right mix between low and high-cost schedules. The right mix has to be the one that leads to a globally optimal solution. The third is that the model does not use gross profit or gross profit per day as a criterion for selecting optimal schedules, which limits the use of the model to only the industrial mode of transport. The fourth is that transport demand is assumed fixed.

Fagerholt (2004) has also developed a computer-based decision support system for fleet scheduling based on heuristic algorithms. Fagerholt et al. (2010) have presented a decision support methodology for strategic planning in tramp and industrial shipping. The proposed methodology combines simulation and optimisation, where a Monte Carlo simulation framework is built around an optimisation-based decision support system for short-term routing and scheduling. Although these research papers have developed algorithms which are flexible, allow interactive user interface, and save time, their exact optimal solution is not guaranteed.

Brown et al. (1987) have developed a scheduling model for ocean transportation of crude oil. In this model, a schedule represents a ship when assigned the transportation of a cargo between its loading port and discharging port. The model aims at minimising total cost of schedules for all ships. It uses an Elastic Set Partitioning algorithm. The review of this model is reported in the follows items. The first is that cargo loading or discharging time window is not considered. The second is that ships are assumed to 
have similar capacity. The third is that full ship loads are assumed. The fourth is that consecutive loads are not allowed because the planning period is too short to accommodate more than one ship load. The fifth is that the model does not use gross profit or gross profit per day as a criterion for selecting optimal schedules. The sixth is that transport demand is assumed fixed. Kim and Loe (1997) have developed a decision support system for ship scheduling in industrial bulk trade. The solution method is similar to what is given by Brown et al. (1987).

Lin and Liu (2011) have considered the ship routing problem of tramp shipping and proposed a combined mathematical model that simultaneously takes into account the ship allocation, freight assignment and ship routing problems. To solve this problem, they have developed an innovative genetic algorithm. The review of this model is reported in the follows items. The first is that multi-commodity concept considered by this model is reduced to maximum one primary cargo and one spot cargo was taken one after the other by any ship voyage. The second is that the model does not use gross profit per day as a criterion for selecting an optimal solution. The third is that transport demand is assumed fixed.

Laake and Zhang (2013) have developed a model to determine the best mix of longterm and spot cargo contracts for a given fleet. The model finds the optimal fleet size and a mix for a set of cargo contracts or a mix of both. The model assumes that transport demand is sufficiently large on each route. Each ship takes full loads and does not mix cargoes from different cargo contracts, which is a standard practice in the coal/ iron ore trade. The review about Lin and Liu paper applies here also.

It was found that the OR model of Osman et al. (1993) and Christiansen et al. (2007) holds characteristics close to the tramp shipping characteristics mentioned at the beginning of this section. The model of either research paper is based on a network of multiple cargo flows. Each network node either represents a load or a discharge event for each cargo. Ships compete in carrying cargoes by following selected arcs in the network, beginning with a start node and ending with an end node. If a network arc is used by a ship, this arc is restricted for use by other ships. An arc is used by a ship if lay can of each arc node can be met and load available in each arc node is within remaining ship capacity. The model assigns network arcs to ships in an attempt to maximise total voyage gross profit for all ships. Both models are nonlinear. Hemmati et al. (2014) and Christiansen and Fagerholt (2014) have presented better tramp shipping characteristics. The former have used a linear objective but used heuristic algorithms to solve their problem. The latter have presented some linear and non-linear models; some handle flexible cargo sizes of what is called 'more or less owner's option', some handle splitting of cargo loads, and some others handle varying ship speed. Most of these models use heuristic algorithms to solve the problem of concern. Flexible cargo sizes, splitting of loads, and different ship speed, although they have been formulated within the models; they could have been handled via sensitivity and what-if analysis after solution. This might help other important shipping elements to be formulated as well. Sensitivity and what-if analysis are necessary validation tools in tramp shipping to handle possible changes in cargo quantity and freight rate, cargo handling rate and charges, and ship speed and fuel consumption. Instead of ship full loads assumed in Brown et al. (1987) and Laake and Zhang (2013), Vilhelmsen et al. (2015) have developed a linear model to handle the case where multiple cargoes can be carried 
simultaneously on board each ship. The review of the previous models is reported in the follows items. The first is that the model objective maximises voyage gross profit, while in tramp shipping the objective has to maximise gross profit per day. The second is that transport demand is assumed deterministic. In shipping, some cargoes may have random demand. The third is that the model with non-linear objective or/and constraints call for software solutions usually less reliable and inefficient. The fourth is that the authors brought no evidence on the possibility of solving large problems when more cargoes and ships are added.

Bakkehaug et al. (2016) and Vilhelmsen et al. (2017) have developed a similar model to schedule the voyages of a fleet of ships considering a minimum time spread between some voyages. The former has used the Adaptive Large Neighborhood Search (ALNS) heuristic to solve the problem, while the latter has used a Decomposition approach with Dynamic Programming algorithm for column generation. Their model focuses on the time spread between voyages in response to a charter party clause which requires the voyages to be 'fairly evenly spread'. This requires the voyage to become the model decision variable with a predetermined route and full-load cargo to be transported in each voyage. This might be true for some contracted cargoes, but not true otherwise. Therefore, these two research papers cannot stand as 'optimisation of ship voyage' research area as defined earlier.

There are three additional review items that cut across all research papers mentioned so far which can be summarised as follows:

a) Model parameters are not verified for validity, using sensitivity and what-if analysis, especially for cargo quantity and freight, cargo handling rate and charges, and ship speed and fuel consumption.

b) Many shipping elements and charter party terms and clauses are not considered. Twenty of such elements and terms are shown in SOS voyager optimisation model.

c) Models need OR skills to use them. In shipping, most users lack such skills.

This review of the literature on 'optimisation of ship voyage' and the review items brought about it reveals the fact that research papers are in common attempting to solve the original problem mentioned at the beginning of this section but with different review comments. Review comments can be sammarised in using a model with deterministic gross profit objective, with little shipping elements and rules, with no checks for validity, and with no facilities for non-OR users to deliver data and to run and interact with the model. This gives rise to the contribution that has been achieved in this paper, namely, the development of an OR-based decision support system which can optimise the ship voyage outcome considering all possible shipping elements and charter party clauses, gross-profit-per-day objective, deterministic and stochastic cargo transport demand, and sensitivity and what-if analysis. The use of gross-profit-per-day objective under deterministic and stochastic cargo transport demand, assuming multiple ships carrying various cargoes simultaneously along with realistic and validated shipping elements and rules, is here presented for the first time in tramp shipping literature. The state-of-the-art Block-Angular Linear Ratio programming methodology is used to solve this formulation (see SOS voyager optimisation model for details). El Noshokaty (1988) has first developed a shipping model with gross profit per day objective for only one ship using Fractional programming methodology. 
Another problem in tramp shipping also exists when there are some ships and some trade areas, and it is required to allocate these ships to these trade areas, in an attempt to identify which trade area best fits the characteristics of each ship. The objective would be to maximise fleet gross profit, subject to available cargo demand in each trade area and yearly working days for each ship. Name this research area 'optimisation of ship allocation'. It goes without saying that this area is of a tactical planning nature, compared to the previous research area which is of an operational planning nature. On 'optimisation of ship allocation' research area, the following research efforts were cited. Tsilingiris (2005) addressed the problem of optimal allocation of ships to shipping lines in liner shipping, which is applicable also to tramp shipping. Two models, published by Jaramillo and Perakis (1991a, 1991b) and Powell and Perakis (1997), were used by Tsilingiris to allocate numbers of ship types to the routes developed in his model. The objective is to find the optimal allocation of ships to routes that minimises total operating and lay-up cost. There are two review items on these research papers. The first is that voyage revenue is assumed fixed, either because cargo mixes are not considered or cargo transport demand is assumed deterministic. This means that revenue is supposed to have no effect on ship voyage and allocation of ships to lines, which is not true. The second is that allocation is done to the number of ships of each ship type, rather than the number of voyages of each ship. Allocation by the number of ships does not permit a ship to work on different lines.

Christiansen et al. (2007) and Fagerholt and Lindstad (2000) discussed an allocation model to allocate voyages of heterogeneous ships to shipping routes. The objective is to find the optimal allocation of ships to routes that minimises total operating cost plus fixed cost. There are three review items on these research papers. The first is that voyage revenue is not included in the model objective, ignoring the effect of revenue on the allocation. The second is that ship fixed cost is associated with the use of the ship. If the ship is laid up (not used), its fixed cost is going to disappear from the objective function. The third is that the model puts a maximum number of voyages for each ship in the planning period. This number is put on the total number of voyages completed by the ship on all routes. Since voyage days are not equal among routes, this number is difficult to calculate.

Vilhelmsen et al. (2013, 2015) explore the tank allocation problem in bulk shipping and devise a heuristic solution method that can find feasible cargo allocations. The method relies on a greedy construction heuristic for finding feasible allocations and local search for improving initially constructed allocations.

The above-mentioned review of literature on 'optimisation of ship allocation' and the review items brought about it gives rise to the contribution that has been achieved in this paper; namely, the development of a decision support system which can optimise ship allocation with an objective function of profit items rather than cost items only; without: a) Restricting assumption on cargo transport demand to be large enough, b) Without restricting assumption on ship working condition to be limited to one area, and c) Without restricting assumption on shipload to be limited to one cargo. It is important at this point to differentiate between the tramp-problem names used in this research paper; namely 'optimisation of ship voyage' and 'optimisation of ship allocation', and the name used in tramp shipping literature as 'tramp ship routing and scheduling problem'. The former names represent an arbitral breakdown of the planning process when compared with that of the latter name. The name 'optimisation of ship voyage', 
which implies both the scheduling and routing processes, cares for the alternative production cycles of the same ship caused by the alternative cargo mixes available for transport. It is given to cargo mix selection made in a short-term plan, say 3 to 4 months at most (as in any ship voyage), whereas the name 'optimisation of ship allocation', which implies the routing process only, cares for the alternative production cycles caused by the alternative trade areas available for service. It is given to allocating ships to trade areas in a long-term plan, say 1 year at least (as in budgeting). 'Optimisation of ship voyage' for a long-term plan is not advised in this research paper, where scheduling process is practically impossible to realise. The reason is that short-term plans, overlapped in a dynamic way, cares for varying and detailed shipping elements and rules. Long term plans, like macro plans, care for aggregated elements and rules. These plans enable handling of many ships and cargoes, which short term plans with detailed elements and rules cannot accommodate without too many complications. And if accommodated, optimisation cannot be done in a reasonable amount of time.

The third problem in tramp shipping also exists when there is a need to appraise a new ship; a ship to be built, purchased, or chartered-in. Name this research area 'new ship appraisal'. This area is of a strategic nature if compared to the above-mentioned two areas.

The reason why the above three research areas were selected among other research areas is that they are totally connected in a series of strategic, tactical, and operational planning. They aim at a common goal of not only improving the return on investment in a cargo transportation domain but also improving the logistics and supply chain systems this domain is part of. Improving ship voyage objective, the way mentioned above cannot contribute positively to this common goal unless ships are allocated profitably among trade areas. Also, existing ships cannot be allocated among trade areas without taking new ships, if any, into account.

The third section discusses 'optimisation of ship voyage', the forth section discusses 'optimisation of ship allocation', and the fifth section discusses 'new ship appraisal', along with the contribution brought in each of these research areas. The sixth section concludes the contribution made in this research paper and suggestions for future research work.

\section{SOS Voyager optimisation}

The first subsection describes the SOS Voyager optimisation model. In the second subsection, sensitivity analysis and what-if analysis are used to validate the model. In the third subsection, a case study is presented to show the application of the model.

\section{SOS Voyager optimisation model}

This OR model aims at finding the optimal cargo mix to be assigned to each ship voyage. Its objective is to maximise the gross profit per day earned by all ships' voyages completed during a certain planning period. A simplified version of this model is displayed in Appendix 1 . The model contains 11 basic elements and rules found in any tramp shipping problem. An extended model has also been developed to include the following 9 additional shipping elements and charter party clauses (refer to SOS, 2018 for details):

a) Already loaded cargo. If loaded, cargo is assigned to the ship already carrying it.

b) Already booked cargo (the term 'booked' is used instead of 'contracted' to cover booking of 'non-contracted' cargoes). If booked, ship name may or may not be 
specified. If the ship name is specified, booked cargo is assigned to this ship. If the ship name is not specified, booked cargo is assigned to the ship contributing more to gross profit per day.

c) Lightening of shipload via SUMED pipeline in Suez Canal.

d) Lightening of shipload via 'daughter-ship arrangement' in Suez Canal or Panama Canal.

e) Additional charter party terms such as specifying multiple ships and cargoes in one charter party, with freight specified for each cargo or lump sum freight for all cargoes.

f) Time charter to be taken as an alternative venture to voyage charter.

g) Deadweights other than winter deadweight; namely summer and tropical deadweights.

h) Weather condition as an element affecting ship speed.

i) Different open and close ports and dates are specified for each ship.

Appendix 1 contains the model objective function, flow constraints, capacity constraints, time constraints, and non-negativity and integrality constraints. The objective function is expressed in total voyage gross profit per day for all ships. The flow constraints connect selected cargo transport links of each ship from voyage beginning to voyage end. They also ensure the flow of at most one transport link towards each cargo. The capacity constraints ensure the ship capacity; expressed in weight, volume, or units, is not violated by the cargo mix selected in each transport link. They also decide whether the ship has to be in a laden or a ballast position when sailing the transport link, and decide whether to pass or bypass the canals and straits. The time constraints ensure the time window allowed for loading or discharging of each cargo is not violated by the time spent in ports and sailing towards the cargo. They also calculate the ship waiting time spent before the opening time of each cargo time window. Also, they ensure the total voyage allowable time is not violated by the actual time. The nonnegativity constraints ensure the model variables do not go negative. The integrality constraints turn the variables, dedicated for the transverse of transport links and chartering-in, to yes-or-no decisions. A chance-constrained (stochastic) version of the model is described at the end of the Appendix. The reason for formulating the model as chance-constrained is that it consumes a smaller number of variables if compared to Dual-Stage or Multi-Stage Stochastic models, which are likely to be beyond practicality for most real linear programming applications.

The contribution made in this model is in the formulation of the objective function so that it represents a stochastic gross profit per day objective, in addition to the formulation of all possible shipping elements and charter party clauses.

\section{SOS Voyager sensitivity and what-if analysis}

Programming algorithms used to solve the above-mentioned optimisation model permits the user to change model parameters after optimisation without the need to reoptimise from the beginning. This permits ship owner to easily change parameters such as cargo freight rate and quantity, cargo handling rate and charges, and ship speed and fuel consumption, in an attempt to see the effect of this change on the optimal 
solution. This permits the user to validate the model in capturing and describing the original problem mentioned in Problem Statement and Review of the Literature in Tramp Shipping Optimisation. In the sensitivity analysis, series of changes are given to SOS Voyager to see how far these changes are effective. In what-if analysis, a single change, in an interactive mode, is input to SOS Voyager to see the effect of this change on the objective function. Speed sensitivity or what-if analysis may be applied to all transport links collectively, or to selective transport links separately. Clicking menu options is all that is needed to perform optimisation, sensitivity, and what-if analysis.

\section{Case study on voyage optimisation}

This case demonstrates the operation of a shipping company, where names and data elements were used to serve the purpose of this research and preserve its confidentiality. It applies the model mentioned in the first subsection and the sensitivity and what-if analysis referred to in the second subsection. It demonstrates the case where using a gross profit objective, with deterministic transport demand is considerably less profitable than using a gross-profit-per-day objective, with stochastic transport demand. El Kosseir, Safaga, and Sidi Kirear are three oil tankers owned by Elesteshary Shipping Company (ESC). In the last quarter of the year 2017, these tankers are planning to compete in carrying ten crude oil cargoes. Three of these cargoes are to be transported from Kuwait to the USA, another three from Ukraine to China, and four from Venezuela to Latvia. Data on tankers, ports, and cargoes can be displayed and extracted using 'Data Entry Main Menu' displayed by SOS Data. Relevant data on ships is shown in Table 1. For El Kosseir and Sidi Kirear, the open port is Alexandria, Egypt. For Safaga, the open port is Odessa. For all ships, the close port is last port of call, the open date is $1 / 10 / 2017(\mathrm{dd} / \mathrm{mm} /$ yyyy is the date format), the close date is $31 / 12 / 2017$, the voyage fixed cost is $\$ 1000$, and the fixed time is 0.3 days. Relevant data on the port is shown in Table 2. Before the open date, ten crude oil cargoes are identified, of which

Table 1 Ship data

\begin{tabular}{|c|c|c|c|}
\hline Ship & El Kossier & Safaga & Sidi Kirear \\
\hline \multicolumn{4}{|l|}{ Data item } \\
\hline -Deadweight in $\mathrm{mt}^{*}$ & 40,000 & 50,000 & 70,000 \\
\hline -Low, medium, and high speed in miles/h & $15 ; 17 ; 19$ & $14 ; 16 ; 18$ & $13 ; 15 ; 17$ \\
\hline $\begin{array}{l}\text {-Main engine laden fuel consumption } \\
\text { in mt/day, each speed level** }\end{array}$ & $16 ; 19 ; 24$ & $14 ; 18 ; 22$ & $13 ; 16 ; 20$ \\
\hline $\begin{array}{l}\text {-Main engine ballast fuel consumption in } \\
\text { mt/day, each speed level }\end{array}$ & $10 ; 13 ; 20$ & $9 ; 12 ; 18$ & $8 ; 11 ; 16$ \\
\hline $\begin{array}{l}\text {-Auxiliary engine fuel consumption } \\
\text { in mt/day }{ }^{* * *}\end{array}$ & 1 & 1 & 1 \\
\hline $\begin{array}{l}\text {-Heating fuel consumption in mt } \\
\text { of main engine fuel/day/100 mt of cargo }\end{array}$ & 0.125 & 0.11 & 0.1 \\
\hline -Sues Canal dues, laden and ballast in US\$ & 158,$960 ; 135,180$ & 172,$310 ; 146,560$ & 185,$650 ; 157,940$ \\
\hline -Panama Canal dues, laden and ballast in US\$ & 79,$000 ; 62,900$ & 98,$250 ; 78,150$ & 117,$500 ; 93,400$ \\
\hline -Bosporus and Dardanelles dues in US\$ & 9640 & 12,150 & 13,850 \\
\hline -Running cost in US\$/day & 5000 & 7000 & 7700 \\
\hline
\end{tabular}

* $\mathrm{mt}=$ metric ton

** Fuel cost for main engine is $450 \mathrm{US} \$ / \mathrm{mt}$

*** Fuel cost for auxiliary engine is $675 \mathrm{US} \$ / \mathrm{mt}$ 
Table 2 Port data

\begin{tabular}{lllll}
\hline $\begin{array}{l}\text { Data item } \\
\text { Port name }\end{array}$ & $\begin{array}{l}\text { Cost/ } \\
\text { call in } \\
\text { US\$ } \\
\text { (Lights, } \\
\text { towage) }\end{array}$ & $\begin{array}{l}\text { Cost/ } \\
\text { day in } \\
\text { US\$ } \\
\text { (Quay } \\
\text { services) }\end{array}$ & $\begin{array}{l}\text { Waiting } \\
\text { days* } \\
\text { (Anchor, } \\
\text { idle) }\end{array}$ & $\begin{array}{l}\text { Cargo } \\
\text { handling } \\
\text { mt/day }\end{array}$ \\
\hline Alexandria (Egypt) & 1500 & 150 & 0 & 34,000 \\
Baltimore & 12,000 & 1200 & 0.3 & 40,000 \\
Shuaiba (Kuwait) & 8000 & 800 & 0.5 & 37,000 \\
Maracaibo & 10,700 & 1070 & 0.5 & 37,000 \\
Odessa & 10,000 & 1000 & 0.5 & 35,000 \\
Riga (Latvia) & 11,000 & 1100 & 0.3 & 35,000 \\
Shanghai & 9000 & 900 & 0.4 & 35,000 \\
\hline
\end{tabular}

* Port waiting days are classified as 'force majeure' and hence are not part of any demurrage or dispatch time counts

seven cargoes have confirmed (offered) quantity and freight and three unconfirmed cargoes (not yet offered). Relevant data on cargo is shown in Table 3. For the three unconfirmed cargoes, ship owner anticipates probabilities for five classes of quantity and freight for each cargo. Ship owner also stipulates, by a least probability, to be able to transport a quantity of each cargo within its transport demand. Additional data of unconfirmed cargo is shown in Table 4. From the seven confirmed cargoes, ship owner needs to know what optimal (best) cargo mix to select for each ship to fix it, taking into account the three unconfirmed cargoes which might be confirmed later on. During initial selection, ship speed is assumed to be at its lowest level. After the initial selection, ship owner needs to have answers to the following questions. What if the unconfirmed cargoes are all disregarded? What is the best optimisation model to use? Can further negotiation with shippers of the seven confirmed cargoes improve voyage gross profit per day? If yes, what cargo is best negotiable and what is the best quantity agreeable to both sides? If the ship speeds up to save some sailing days, do these days allow

Table 3 Cargo data

\begin{tabular}{|c|c|c|c|c|c|c|c|}
\hline $\begin{array}{l}\text { Data item } \\
\text { Cargo** }^{* *}\end{array}$ & $\begin{array}{l}\text { Shipping } \\
\text { event }\end{array}$ & Load port & $\begin{array}{l}\text { Load } \\
\text { Laycan }\end{array}$ & $\begin{array}{l}\text { Discharge } \\
\text { port }\end{array}$ & $\begin{array}{l}\text { Discharge } \\
\text { Laycan }\end{array}$ & $\begin{array}{l}\text { Weight } \\
\text { in mt }\end{array}$ & $\begin{array}{l}\text { Freight } \\
\text { In US\$/ } \\
m t^{* * *}\end{array}$ \\
\hline Crude Oil 1 & Offered & Shuaiba & $1-10 / 10$ & Baltimore & $1-10 / 11$ & 40,000 & 50 \\
\hline Crude Oil 2 & Offered & Shuaiba & $20-27 / 10$ & Baltimore & $20-27 / 11$ & 60,000 & 60 \\
\hline Crude Oil 3 & Offered & Odessa & $5-15 / 10$ & Shanghai & $5-15 / 11$ & 35,000 & 40 \\
\hline Crude Oil 4 & Offered & Odessa & $3-16 / 11$ & Shanghai & $3-16 / 12$ & 40,000 & 50 \\
\hline Crude Oil 5 & Offered & Maracaibo & $5-15 / 12$ & Riga & $20-30 / 12$ & 30,000 & 30 \\
\hline Crude Oil 6 & Offered & Maracaibo & $20-30 / 11$ & Riga & $10-25 / 12$ & 45,000 & 35 \\
\hline Crude Oil 7 & Offered & Maracaibo & $1-10 / 12$ & Riga & $20-30 / 12$ & 40,000 & 40 \\
\hline Crude Oil 8 & Unconfirmed & Shuaiba & $1-31 / 10$ & Baltimore & $1-30 / 11$ & $u c^{*}$ & uc \\
\hline Crude Oil 9 & Unconfirmed & Odessa & $1-30 / 11$ & Shanghai & $1-31 / 12$ & uc & uc \\
\hline Crude Oil 10 & Unconfirmed & Maracaibo & $1-30 / 11$ & Riga & $1-30 / 11$ & uc & uc \\
\hline
\end{tabular}

* uc = unconfirmed quantity or freight 1.5 days waiting) or via Suez Canal (8602 miles with 2 days waiting), Crude Oil 3, 4, and 9 are transported directly (14,169 miles with 1 day waiting) or via Suez Canal (8264 miles with 1 day waiting), and Crude Oil 5, 6, 7, and 10 are transported only directly ( 5274 miles with 0.5 day waiting). Distance between ballast transport links may be found in any distance table (waiting days are assumed zero for these links).

*** Freight is free in and out (FIO) base, load or discharge laydays are restricted to $35,000 \mathrm{mt}$ per day, reversible laydays are subject to demurrage rate of US\$ 8000 per day, and dispatch rate of US\$4000 per day 
Table 4 Unconfirmed cargo additional data

\begin{tabular}{|c|c|c|c|}
\hline $\begin{array}{l}\text { Cargo } \\
\text { Data item }\end{array}$ & $\begin{array}{l}\text { Crude } \\
\text { Oil } 8\end{array}$ & $\begin{array}{l}\text { Crude } \\
\text { Oil } 9\end{array}$ & $\begin{array}{l}\text { Crude } \\
\text { Oil } 10\end{array}$ \\
\hline \multicolumn{4}{|l|}{ Class 1} \\
\hline Weight in $\mathrm{mt}$ & 45,000 & 40,000 & 30,000 \\
\hline Freight in US\$/mt & 50 & 45 & 35 \\
\hline Probability in \% & 5 & 10 & 5 \\
\hline \multicolumn{4}{|l|}{ Class 2} \\
\hline Weight in mt & 47,000 & 42,000 & 32,000 \\
\hline Freight in US\$/mt & 50 & 45 & 35 \\
\hline Probability in \% & 15 & 25 & 15 \\
\hline \multicolumn{4}{|l|}{ Class 3} \\
\hline Weight in mt & 49,000 & 44,000 & 34,000 \\
\hline Freight in US\$/mt & 50 & 45 & 35 \\
\hline Probability in \% & 50 & 40 & 60 \\
\hline \multicolumn{4}{|l|}{ Class 4} \\
\hline Weight in $\mathrm{mt}$ & 51,000 & 46,000 & 36,000 \\
\hline Freight in US\$/mt & 50 & 45 & 35 \\
\hline Probability in \% & 20 & 15 & 15 \\
\hline \multicolumn{4}{|l|}{ Class 5} \\
\hline Weight in $\mathrm{mt}$ & 53,000 & 48,000 & 38,000 \\
\hline Freight in US\$/mt & 50 & 45 & 35 \\
\hline Probability in \% & 10 & 10 & 5 \\
\hline
\end{tabular}

the ship to meet lay can of more cargoes and therefore improve voyage gross profit per day? If yes, on what leg should the ship speeds up and sails on what speed?

At the beginning, SOS Voyager optimisation model is used to find the optimal (best) cargo mix for each ship. Data in Table 4 is turned to deterministic-equivalent quantities as shown in Table 5 (see end of Appendix 1 for details).

Although the number of cargoes is limited, Table 3 amended by Table 5 reads many alternative cargo mixes for each ship. When 'Tramp Shipping Optimisation Main Menu' of SOS Voyager is displayed and when 'Optimisation and Sensitivity Analysis' option is selected from the menu, the sensitivity analysis is reported as in Table 6. To reach the stage where Table 6 is reported, SOS Voyager, as a decision support system, must do a lot of tasks. Details of these tasks are included in Appendix 4.

The model report for high-speed shown in Table 6 is broken down into the voyage details displayed in Table 7 .

Suppose now that unconfirmed cargoes: 'Crude Oil 8, 'Crude Oil 9', and 'Crude Oil 10 ' are discarded, the profit-per-day criterion is also discarded and gross profit objective

Table 5 Unconfirmed cargo deterministic-equivalent quantity and freight

\begin{tabular}{llll}
\hline Cargo Data item & Crude Oil 8 & Crude Oil 9 & Crude Oil 10 \\
\hline Weight in $\mathrm{mt}$ & 51,000 & 42,000 & 36,000 \\
Freight in US\$/mt & 50 & 45 & 35 \\
Least probability of transporting cargo quantity in \% & 70 & 95 & 40 \\
\hline
\end{tabular}


Table 6 Cargo mix, route, and gross-profit-per-day reported by the model (with gross profit per day objective) for each ship, classified by speed level

\begin{tabular}{|c|c|c|c|c|}
\hline $\begin{array}{l}\text { Ship } \\
\text { Speed level }\end{array}$ & El Kosseir & Safaga & Sidi Kirear & $\begin{array}{l}\text { Gross profit per } \\
\text { day in US\$ }\end{array}$ \\
\hline Cargo mix & Crude oil 10 & Crude Oil 6 & Crude oil 2, 5, and 7 & \\
\hline Low & & & & 52,148 \\
\hline Route & Maracibo-Riga & Maracibo- Riga & $\begin{array}{l}\text { Shuaiba-Baltimore } \\
\text { (directly)-Maracibo-Riga }\end{array}$ & \\
\hline Cargo mix & Crude oil 1 and 10 & Crude Oil 6 & Crude oil 2, 5, and 7 & \\
\hline Medium & & & & 70,463 \\
\hline Route & $\begin{array}{l}\text { Shuaiba-Baltimore } \\
\text { (directly)-Maracibo-Riga }\end{array}$ & Maracibo- Riga & $\begin{array}{l}\text { Shuaiba-Baltimore } \\
\text { (directly)-Maracibo-Riga }\end{array}$ & \\
\hline Cargo mix & Crude oil 1 & Crude oil 6 and 10 & Crude oil 2, 5, and 7 & \\
\hline High & & & & 79,671 \\
\hline Route & $\begin{array}{l}\text { Shuaiba-Baltimore } \\
\text { (directly) }\end{array}$ & Maracibo- Riga & $\begin{array}{l}\text { Shuaiba-Baltimore } \\
\text { (directly)-Maracibo, Riga }\end{array}$ & \\
\hline
\end{tabular}

is used instead (which can be handled also by SOS Voyager). Table 8 displays results of this supposed case, assuming all ships are at high speed.

Table 8 is broken down into the voyage details displayed in Table 9 .

The following are some analysis made upon examining Tables 6 to 9:

a) The number of alternative cargo mixes in the model is enormous and thus cannot be manually enumerated. It takes SOS Voyager 1 min to process the model.

Hardware used is Intel i3 PC (64-bit). Software used is MS Windows 7. MS Access 2007 is used as a front-end database system, while MS SQL Server 2008 is used as a back-end database to permit data to expand and to be updated from different network entry points, locally and remotely. Microsoft Message Passing Interface (MS MPI) is used for parallel processing. Processes may be distributed among cores of one PC or cores of multiple PCs in a network. The 1 min was taken on one i3 PC. Using old software versions has no effect on model performance if compared to computer hardware and network facilities. SOS is designed primarily to handle a scale of up to 30 ships and 30 cargoes. Although time was not recorded for such scale, an experiment was made which may be used as a guide to estimate processing time, that is to run the model for one ship and 30 cargoes. The reason why only one ship is chosen is that the algorithm used to process the model can decompose the shipping problem into sub problems, one for each ship. Meanwhile, MS MPI can process the 30 sub-problems in parallel with each sub-problem using one processor core. It takes SOS Voyager 58 min to process the model for 1-ship-30-cargo

Table 7 Voyage details reported by the model (with gross profit per day objective) for each ship, at high speed

\begin{tabular}{lllll}
\hline $\begin{array}{l}\text { Ship } \\
\text { Voyage details }\end{array}$ & $\begin{array}{l}\text { El } \\
\text { Kosseir }\end{array}$ & Safaga & $\begin{array}{l}\text { Sidi } \\
\text { Kirear }\end{array}$ & Total \\
\hline Gross profit (\$) & 752,534 & $1,145,939$ & $3,520,082$ & $5,418,555$ \\
Days & 34.4 & 75.5 & 82.6 & 192.5 \\
Gross profit/day (\$) & 21,877 & 15,178 & 42,616 & 79,671 \\
\hline
\end{tabular}


Table 8 Cargo mix, route, and gross profit reported by the model (with gross profit objective) for each ship, at high speed

\begin{tabular}{|c|c|c|c|c|}
\hline $\begin{array}{l}\text { Ship } \\
\text { Speed level }\end{array}$ & El Kosseir & Safaga & Sidi Kirear & $\begin{array}{l}\text { Gross profit } \\
\text { in US\$ }\end{array}$ \\
\hline Cargo mix & Crude oil 1 and 4 & Crude oil 3 and 6 & Crude oil 2, 5, and 7 & \\
\hline High & & & & $5,475,997$ \\
\hline Route & $\begin{array}{l}\text { Shuaiba-Baltimore(directly)- } \\
\text { Odessa-Shangahai } \\
\text { (via Suez Canal) }\end{array}$ & $\begin{array}{l}\text { Odessa -Shangahai } \\
\text { (via Suez Canal)-Maracibo-Riga } \\
\text { (via Panama Canal) }\end{array}$ & $\begin{array}{l}\text { Shuaiba-Baltimore } \\
\text { (directly)-Maracibo-Riga }\end{array}$ & \\
\hline
\end{tabular}

scale, using the above-mentioned hardware and software. Remember that the model has a gross-profit-per-day objective which requires additional algorithms and contains all possible shipping elements and charter party clauses which require additional constraints. Add to this the fact that the 30 cargoes create an enormous number of alternative transport links which requires additional variables. These requirements demand considerable processing time. It goes without saying that problem scale and timing rely heavily on computer hardware and network architecture, e.g. a supercomputer will dropdown processing time considerably. The software is designed carefully to handle large-scale problems. It should be noted in this respect that the 30-ship limit is put on the number of ships of the same type that could compete in carrying same cargoes in the same planning period. Likewise, the 30cargo limit is put on the number of cargoes of the same type that are available for transport on board these ships in the same planning period. To handle the case of 30 or more cargoes when computing resources are limited in speed, the user may partition the planning period, say 3 months, into smaller ones, say 1 month each. In this case, the optimal cargo mix selected for a certain ship in 1-month planning period is considered as already discharged, still loaded, or still booked for this ship in the next planning period, where planning periods may overlap. In the next planning period, new cargoes may be added as being offered or not-yet-offered. The advantage of this arrangement is not only to handle a smaller number of cargoes in each period but also to incorporate changing shipping elements over time. The disadvantage is to lose a longer term planning.

b) In this case study, speed sensitivity analysis concludes that the higher speed is tried on all legs the more gross profit per day or gross profit is achieved. Higher speed enabled each ship to meet lay can dates of more profitable cargoes. One can expect better results if higher speed is tried only on legs leading to these cargoes.

Sensitivity analysis may also be tried for cargo freight and quantity, and cargo handling rate and charges. Take for now handling rate as an example. There is a chance that handling rate in Maracaibo be decreased to $17,000 \mathrm{mt} /$ day due to

Table 9 Voyage details reported by the model (with gross profit objective) for each ship, at high speed

\begin{tabular}{lllll}
\hline $\begin{array}{l}\text { Ship } \\
\text { Voyage details }\end{array}$ & $\begin{array}{l}\text { El } \\
\text { Kosseir }\end{array}$ & Safaga & $\begin{array}{l}\text { Sidi } \\
\text { Kirear }\end{array}$ & Total \\
\hline Gross profit (\$) & $1,285,528$ & 670,383 & $3,520,086$ & $5,475,997$ \\
Days & 69.1 & 74.1 & 82.6 & 225.8 \\
Gross profit/day (\$) & 18,604 & 9047 & 42,616 & 70,267 \\
\hline
\end{tabular}


pumps repeated malfunction. There is also another chance that by the time Sidi Kirear reaches Maracaibo in early December to take 'Crude Oil 5' and 'Crude Oil 7', handling rate could possibly reach 57,000 $\mathrm{mt}$ per day. This may be caused by the installation of high-speed pumps. Applying handling sensitivity to the model at lowspeed results the same quantities as what were reported earlier, for the two handling rates available for Sidi Kirear while loading 'Crude Oil 5' and 'Crude Oil 7'. The only difference between the two rates is that total gross profit per day decreases to $\$$ 51,521 for $17,000 \mathrm{mt} /$ day and increases to $\$ 52,339$ for $57,000 \mathrm{mt} /$ day handling rate.

c) In comparison between Tables 7 and 9, one can notice that the model can increase gross profit per day by $\$ 9404$ (13\%) while maintaining same gross profit as that given by Table 9 (think of the percentage improvement in gross profit per day if the ship owner adopts the ship full-load-and-down criterion). With full confidence in probabilities shown in Tables 4 and 5 , this analysis recommends that unconfirmed 'Crude Oil 10' suggested by Table 7 is better being selected instead of confirmed 'Crude Oil 3' and 'Crude Oil 4' suggested by Table 9. As perhaps noticed, if the ship operator decides on the cargo mix suggested by Table 9 , he will not be able to select 'Crude Oil 10' when it is confirmed later on, losing \$ 9404 gross profit per day. The previous analysis suggests also that stochastic gross profit per day is expected to be more profitable than stochastic gross profit.

d) If probability distribution cannot be identified for cargo transport demand, then the model can be used along with quantity-and-freight sensitivity analysis of unconfirmed cargoes. In this case, ship owner's own judgment is needed to select between the alternative outcomes of sensitivity analysis. This analysis will leave gross profit criterion the last choice in selecting the optimal cargo mix. To explain, suppose 'Crude Oil 9' and 'Crude Oil 10' become confirmed with quantities and freights shown in Table 5, while 'Crude Oil 8' is still unconfirmed with no such probability distribution as shown in Table 4. Suppose now that ship owner wants to evaluate the effect of 'Crude Oil 8' quantityand-freight change on gross profit per day at low ship speed, namely at quantities of $35,000 \mathrm{mt}, 45,000 \mathrm{mt}$, and 55,000 mt with freights of $\$ 60, \$ 55$, and $\$ 50$, respectively. Applying gross profit per day objective, with quantity and freight sensitivity analysis, results the same as what is given by the model at low speed, for all quantities. In other words, the objective is not sensitive to the change in the quantity and freight of 'Crude Oil 8'. This analysis suggests the use of stochastic gross profit per day or gross profit per day when compared to gross profit.

e) The above-mentioned analysis assumes same ship speed on all sailing legs. The following discussion reports the analysis made on selected sailing legs in the model. Suppose the ship owner wants to study the effect of accelerating ship speed of Sidi Kirear in its way to discharge 'Crude Oil 5' and 'Crude Oil 7', to medium and high speed. This is an attempt from ship owner to stop the decrease of gross profit per day caused by the 17,000 $\mathrm{mt} /$ day low handling rate in Maracaibo, which is more likely to occur by the time these cargoes are being loaded. The analysis reports the same quantities as what was reported earlier, but with \$52,993 for medium ship speed and \$ 54,098 for high speed. 
f) The above-mentioned analysis uses sensitivity analysis. What-if analysis may also be applied after optimisation has taken place, with or without sensitivity analysis, to show the effect of only one change level in model parameter, whether the model is of voyage gross profit or gross profit per day. Cargo freight rate and quantity, cargo handling rate and charges, and ship speed and fuel consumption are examples of such parameters.

g) The above-mentioned analysis assumes all ships are owned. What if the ship owner decides to charter-in a ship as to compete in carrying 'Crude Oil 6' for example? The estimated gross profit of the chartered-in ship is \$ 400,000 in 25 days with $\$$ 1000 voyage fixed cost and 1 day voyage fixed time. Assuming ship low-speed with no sensitivity analysis applied to the model, the result would be: carry 'Crude Oil 4' by Safaga via Sues Canal, 'Crude Oil 10' by El Kosseir directly, 'Crude Oil 2' followed by 'Crude Oil 5' and 'Crude Oil 7' by Sidi Kirear, all directly, then 'Crude Oil 6' by the chartered-in ship. Total gross profit per day would be $\$ 65,969$.

h) Optimisation sessions may be repeated once again later; say next month. At that time, old offers may become fixed or loaded, not-yet-offered cargoes may become offered, and new offers and probable cargoes may be added.

The above-mentioned analysis recommends the use of stochastic gross profit per day objective and the use of gross profit per day objective plus quantity-and-freight sensitivity analysis of unconfirmed cargoes in case probability distribution cannot be identified for cargo transport demand. The analysis does not recommend the use of gross profit objective or stochastic gross profit objective, as they are expected to give less profit per year. The key elements in the previous analysis are 'gross profit per day objective' along with 'stochastic cargo transport demand' and 'optimisation with sensitivity and what-if analysis'. Owners of tramp shipping systems or any tramp-like transport systems; namely those of cargo airplanes, trains, and trucks, are encouraged to adopt management policies that maintain these key elements.

\section{SOS Allocator optimisation}

The following subsection describes the SOS Allocation model, followed by a subsection to demonstrate a useful application of this model; a case study on port development.

\section{SOS allocation model}

SOS Allocator optimisation model is here presented to allocate existing ships to cargo trade areas and to determine the yearly frequency of calls each ship completes in each area. The model is displayed in Appendix 2. The model contains an objective function, time constraints put on total days spent by each ship each year on all trade areas, quantity constraints put on total weight of cargoes carried by all ships in each trade area each year, and non-negativity and integrality of model variables. The objective function equals to yearly fleet gross profit minus cost of fleet layup days. The gross-profit-perday objective is not considered here because the planning period is fixed for 1 year. If compared to liner shipping, more constraints are added to ensure that the fleet carries booked cargoes. 
The contribution made in this model is in the formulation of the objective function so that it represents a gross profit rather than mere cost items. The contribution is also in the use of gross profit generated from an integrated system like SOS Voyager, assuming realistic cargo transport demand, deterministic or stochastic, available on each cargo trade area. In this model, each ship can work on more than one trade area and to load more than one cargo. SOS may always roll back to SOS Voyager in case its parameters, as described in the next section, are subject to change. In this case, another SOS Allocator session is tried. It goes without saying that the more model parameters are truly representing all possible maritime logistics, the more rigorous is the demand assess on port services. Model validity is guaranteed by the sensitivity and what-if analysis used by the model, as described in next section.

\section{Case study on port development}

The purpose of this case is to show the application of the model mentioned in SOS Allocation model. A shipping research institute called Shipping Research Center (SRC) is now preparing a report on world port development for year 2018. To cover the oil trade part of this report, SRC decided to consult several oil shipping companies on their next year operational plan, as to size the demand on world port services for oil trade. One of these companies is called Elesteshary Shipping Company (ESC), which owns six oil tankers of types used in the marketplace. For the purpose of this research, consider this number of tankers as actually representing the oil shipping industry. To prepare the operational plan for the year 2018, ESC decided to revise the current allocation of ships to oil trade areas. For this purpose, ESC tried to figure out different voyages for each ship, one in each trade area. Cargo transport demand (quantity and freight rate) was then anticipated for a most-likely voyage most presenting each trade area. SOS Voyager was then run to calculate voyage gross profit for each ship on each trade area. Voyages failed to earn any gross profit were discarded. SOS Allocator was then run to see what ship best fits on which trade area, and the frequency of calls it best completes in this trade area. In Table 10, data required for SOS Allocator is displayed by ship working days and daily fixed cost in the year 2018. Trade area minimum and maximum frequency of calls in the year 2018 is displayed in Table 11. The mostlikely voyage gross profit in the year 2018 classified by ship and trade area is displayed in Table 12. Average voyage time in the year 2018, classified by ship and trade area, is also shown in Table 13.

To describe how data in Tables 12 and 13 is calculated, take ship El Kossier as an example when it works on Arabian-Gulf-US trade area. According to SOS Voyager, El

Table 10 Ship yearly working days and daily fixed cost in 2018

\begin{tabular}{lll}
\hline Ship name & Yearly working days & Daily fixed cost (US\$) \\
\hline El Kosseir & 350 & 2000 \\
Ibn Elwaleed & 345 & 2700 \\
Ibn Maged & 345 & 2650 \\
Mersa Alam & 355 & 1700 \\
Safaga & 350 & 7000 \\
Sidi Kirear & 360 & 2100 \\
\hline
\end{tabular}


Table 11 Trade areas and their minimum and maximum frequency of calls in 2018

\begin{tabular}{lll}
\hline Trade area & Min frequency of calls & Max frequency of calls \\
\hline Arabian-Gulf-US & 5 & 28 \\
Black-Sea-Far-East & 6 & 24 \\
Latin-America-Black-Sea & 3 & 12 \\
North-Africa-South-Europe & 10 & 36 \\
West-Africa-North-Europe & 2 & 9 \\
\hline
\end{tabular}

Kossier earned last quarter of the year 2017 a gross profit of $\$ 710,500$ in a 30-day voyage, where 15-knot speed is assumed and some unconfirmed cargoes are considered. This data is chosen to represent the result of El Kossier when it works on ArabianGulf-US trade area in the year 2018. It appears as one entry in Tables 12 or 13. So, these tables present all candidate alternatives of voyage gross profits and days for all ships in all trade areas, calculated per an anticipated cargo transport demand in each trade area. Table 10 presents the supply of ships in terms of available working days and ship daily fixed cost per the year 2018, while Table 11 presents the minimum and maximum frequency of calls in each trade area. Data in Tables 10 and 11 is input to SOS Data (the SOS database), while SOS Voyager generates data in Tables 12 and 13.

Using SOS Allocator model, given data in Tables 12 and 13, it is required to find the optimal allocation of ships to trade areas and lay-up days of each ship satisfying data in Tables 10 and 11. If SOS Allocator finds that the total required voyage days is less than the available working days, some ships have to layup for sometimes (case where $\sum_{j \in L} t_{i j-}$ $x_{i j}$ is less than $D_{i}$ in (30) of Appendix 2). On the other hand, if SOS Allocator finds that the total required voyage days is greater than the available working days, service on some trade areas has to lower its capacity or stop (case where $\sum_{i \in S} x_{i j}$ is less than $F_{j}$ and is greater than or equal to $f_{j}$ in (32) of Appendix 2).

The optimal fleet calling frequencies in year 2018 reported by SOS Allocator is displayed in Table 14, classified by ship and trade area. Total gross profit for all ships is $\$$ $41,363,850$. SOS Allocator report, although it tells us the best trade area on which each ship may service, it shows a long layup for Ibn Elwaleed (219 days) and Ibn Maged (165 days) and a shortage in servicing Arabian-Gulf-US trade area (9 calling frequencies). Table 12 indicates that operation of Ibn Elwaleed and Ibn Maged is not profitable in Arabian-Gulf-US trade area. This might suggest the development of another solution

Table 12 The most-likely voyage gross profit (US\$) in 2018, classified by ship and trade area

\begin{tabular}{llllll}
\hline Trade area & $\begin{array}{l}\text { Arabian-Gulf- } \\
\text { US }^{\mathrm{a}}\end{array}$ & $\begin{array}{l}\text { Black-Sea-Far- } \\
\text { East }^{\mathrm{a}}\end{array}$ & $\begin{array}{l}\text { Latin-America- } \\
\text { Black-Sea }\end{array}$ & $\begin{array}{l}\text { North-Africa- } \\
\text { South-Europe }\end{array}$ & $\begin{array}{l}\text { West-Africa- } \\
\text { North-Europe }\end{array}$ \\
\hline El Kosseir & 710,500 & 620,100 & 510,300 & $n p^{\mathrm{b}}$ & 310,100 \\
Ibn Elwaleed & $\mathrm{np}$ & $\mathrm{np}$ & $\mathrm{np}$ & 116,500 & 342,200 \\
Ibn Maged & $\mathrm{np}$ & $\mathrm{np}$ & $\mathrm{np}$ & 125,100 & 290,200 \\
Mersa Alam & $\mathrm{np}$ & 601,500 & 524,600 & 166,200 & 328,500 \\
Safaga & 730,800 & 650,200 & 581,100 & $\mathrm{np}$ & 365,200 \\
Sidi Kirear & 784,000 & 694,300 & 600,600 & $\mathrm{np}$ & 355,200 \\
\hline
\end{tabular}

an Arabian-Gulf-US trade area, ships do not pass Suez Canal, while in Black-Sea-Far-East trade area, ships pass Suez Canal ${ }^{\mathrm{b}} \mathrm{p}=$ not profitable 
Table 13 Average voyage time ${ }^{a}$ (days) in 2018, classified by ship and trade area

\begin{tabular}{llllll}
\hline Trade area & $\begin{array}{l}\text { Arabian-Gulf- } \\
\text { US }^{\mathrm{b}}\end{array}$ & $\begin{array}{l}\text { Black-Sea- } \\
\text { Far-East }^{\mathrm{b}}\end{array}$ & $\begin{array}{l}\text { Latin-America- } \\
\text { Black-Sea }\end{array}$ & $\begin{array}{l}\text { North-Africa- } \\
\text { South-Europe }\end{array}$ & $\begin{array}{l}\text { West-Africa- } \\
\text { North-Europe }\end{array}$ \\
\hline El Kosseir & 30 & 24 & 17 & $n p^{c}$ & 12 \\
Ibn Elwaleed & $\mathrm{np}$ & $\mathrm{np}$ & $\mathrm{np}$ & 5 & 14 \\
Ibn Maged & $\mathrm{np}$ & $\mathrm{np}$ & $\mathrm{np}$ & 5 & 11 \\
Mersa Alam & $\mathrm{np}$ & 27 & 20 & 7 & 13 \\
Safaga & 32 & 26 & 18 & $\mathrm{np}$ & 15 \\
Sidi Kirear & 35 & 27 & 19 & $\mathrm{np}$ & 14 \\
\hline
\end{tabular}

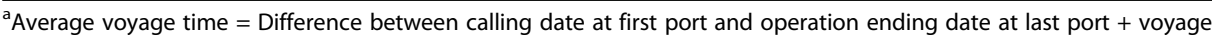
fixed time

${ }^{b}$ In Arabian-Gulf-US trade area, ships do not pass Suez Canal; while in Black-Sea-Far-East trade area, ships pass Suez Canal ${ }^{\mathrm{c}} \mathrm{np}=$ not profitable

where Ibn Elwaleed and Ibn Maged work on trade areas other than Arabian-Gulf-US to avoid layup cost and let other ships work on Arabian-Gulf-US to fulfill the frequency of calls required in this area. Apparently, SOS Allocator model has not considered this solution as optimal since it is going to yield a total gross profit of less than $\$$ $41,363,850$. It is important to notify that Table 14 could have taken another format where its rows being divided into classes, where each class represents a ship tonnage. Each class may then be further divided into rows, with a row for each ship belonging to this class. This format is helpful for the port operator in case dues are fixed for each class of tonnage (this arrangement requires inequality (32) of Appendix 2 to be formulated for each class of tonnage in each trade area).

It goes without saying that any improvement in voyage gross profit or time in any trade area will affect the model optimal solution. This improvement may be caused by improvements in port dues and waiting time, cargo handling rate and charges, sailing time and fuel cost, and canal dues and transit time. Improvement may also be achieved by fair freight rates set by the marketplace for each trade area. For this research, improvement is limited to Arabian-Gulf-US trade area only, caused by an improvement in port dues. This includes reduced dues for all tonnages and extra reduced dues for smaller ones. Refer to SOS (2018) for using SOS Voyager to enforce improvements other than port dues and time. Several improvements in port dues were tried through SOS Voyager and then passed to SOS Allocator to see the optimal improvement in voyage gross profit and time which may cause a shortage in calling frequencies in Arabian-Gulf-US trade area to disappear and layup days of Ibn Elwaleed and Ibn Maged to diminish; while maintaining maximum total port revenue. This optimal improvement in voyage gross profit and time in Arabian-Gulf-US trade area is displayed in Table 15. Its corresponding optimal fleet calling frequencies in the year 2018, after improvement, is shown in Table 16. Total gross profit for all ships is $\$ 48,868,100$.

The purpose of the analysis mentioned so far is to draw the attention to the chances to be taken in port development from the interest of both the ship owner and port operator simultaneously. The analysis is just proposing a shipping trade area improvement against an optimal calling frequency to be completed in this area. The analysis may easily extend to ship types other than oil tankers. It also may extend to utilities other than ports; namely canals and straits. In case ESC fails to represent the oil shipping business, then SRC may either consider dummy tankers in an attempt to simulate real oil 
Table 14 Optimal fleet calling frequencies in 2018, classified by ship and trade area

\begin{tabular}{lllllll}
\hline Trade area & $\begin{array}{l}\text { Arabian- } \\
\text { Gulf-US }\end{array}$ & $\begin{array}{l}\text { Black-Sea- } \\
\text { Far-East }\end{array}$ & $\begin{array}{l}\text { Latin-America- } \\
\text { Black-Sea }\end{array}$ & $\begin{array}{l}\text { North-Africa- } \\
\text { South-Europe }\end{array}$ & $\begin{array}{l}\text { West-Africa- } \\
\text { North-Europe }\end{array}$ & $\begin{array}{l}\text { Layup } \\
\text { days }\end{array}$ \\
Ship name & 10 & 2 & - & - & - & 2 \\
\hline El Kosseir & - & - & - & - & 9 & 165 \\
Ibn Elwaleed & - & - & - & 36 & - & 4 \\
Ibn Maged & - & 13 & - & - & - & - \\
Mersa Alam & 9 & 1 & 2 & - & - & - \\
Safaga & - & 7 & 9 & - & - & \\
Sidi Kirear & 9 & 1 & 1 & - & & \\
$\begin{array}{l}\text { Shortage in calling } \\
\text { frequencies }\end{array}$ & 9 & & & & &
\end{tabular}

shipping business or, assemble results of ESC-like companies in an effort to reach a global solution for port development. In both cases, SOS-like systems remain the tool in doing this. In case the port is servicing more than one ship type, the conflict between types of services is not assumed in this research paper.

It takes SOS Allocator 1 second to process the model. Hardware used is Intel i3 PC. Software used are MS Windows 7, MS Access 2007 (front end), MS SQL Server 2008 (back end), and Microsoft Message Passing Interface (for parallel processing). No limits are imposed by SOS on number of ships or the number of trade areas.

\section{Ship Appraiser}

The following subsection describes the SOS Appraiser model, followed by a subsection to demonstrate a case study.

\section{Ship Appraiser model}

If one of the fleet units allocated by SOS Allocator is a new ship to be appraised for purchasing, building, or chartering-in, and such an allocation is tried for each year of the ship's lifetime, SOS Appraiser may then be used in appraising its worthiness. SOS Appraiser aims at discounting ship gross profit plus other cash flow data obtained throughout ship lifetime and comparing the discounted value with the price of the ship. The model is displayed in Appendix 3. The model contains the Net Present Value formula, which unlike other NPV formulas can produce three net present values. This is attributed to the fact that cargo transport demand in tramp shipping is considered stochastic for many cargoes, if compared to liner shipping. For stochastic cargo transport demand, SOS Voyager can calculate a voyage gross profit corresponding to demand

Table 15 Improved voyage gross profit and time in Arabian-Gulf-US trade area, classified by ship

\begin{tabular}{lll}
\hline Ship name & Voyage gross profit (US\$) & Voyage time (days) \\
\hline El Kosseir & 760,000 & 30 \\
Ibn Elwaleed & 594,000 & 35 \\
Ibn Maged & 530,500 & 28 \\
Mersa Alam & $\mathrm{np}$ & $\mathrm{np}$ \\
Safaga & 790,500 & 32 \\
Sidi Kirear & 870,000 & 35 \\
\hline
\end{tabular}


Table 16 Optimal fleet calling frequencies in 2018, after improvement, classified by ship and trade area

\begin{tabular}{lllllll}
\hline Trade area & $\begin{array}{l}\text { Arabian- } \\
\text { Gulf-US }\end{array}$ & $\begin{array}{l}\text { Black-Sea- } \\
\text { Far-East }\end{array}$ & $\begin{array}{l}\text { Latin-America- } \\
\text { Black-Sea }\end{array}$ & $\begin{array}{l}\text { North-Africa- } \\
\text { South-Europe }\end{array}$ & $\begin{array}{l}\text { West-Africa- } \\
\text { North-Europe }\end{array}$ & $\begin{array}{l}\text { Layup } \\
\text { days }\end{array}$ \\
Ship name & 9 & 3 & - & - & - & 8 \\
\hline El Kosseir & 6 & - & - & - & - & 4 \\
Ibn Elwaleed & 12 & - & - & 1 & - & 2 \\
Ibn Maged & - & 4 & - & 35 & - & 4 \\
Mersa Alam & - & 5 & 12 & - & - & 1 \\
Safaga & 1 & 12 & - & - & - & - \\
Sidi Kirear & - & - & - & - & & \\
$\begin{array}{l}\text { Shortage in calling } \\
\text { frequencies }\end{array}$ & - & & & & &
\end{tabular}

upper limit (best case scenario), deterministic-equivalent value (most likely case), and lower limit (worst case). The three values of gross profit are passed to SOS Allocator and then to SOS Appraiser to calculate the three net present values.

As it is now clear, SOS Voyager followed by SOS Allocator is used to calculate the yearly gross profit needed by SOS Appraiser model. Programming algorithms used to solve SOS Voyager optimisation models permit the ship owner to change model parameters after optimisation without the need to re-optimise them from the beginning. This permits ship owner to easily change parameters such as cargo freight rate and quantity, port cargo handling rate and charges, and ship speed and fuel consumption, to see the effect of this change on the optimal solution. This permits the ship owner to validate the models used by SOS Voyager. In the sensitivity analysis, series of changes are given to SOS Voyager to see how far these changes are effective. In what-if analysis, a single change, in an interactive mode, is input to SOS Voyager to see the effect of this change on the objective function. Speed sensitivity or what-if analysis may be applied to all transport links, collectively, or to selective transport links, separately. Clicking menu options is all that is needed to perform optimisation, sensitivity, and what-if analysis. When a new ship is appraised, SOS Voyager is used to calculate its gross-profit-per-day for each voyage completed on each trade area, along with sensitivity and what-if analysis of cargo quantity and freight. Since ship appraisal model cares for futuristic values of its parameters, stochastic rather than deterministic cargo transport demand is considered, especially in the case of tramp shipping. Three sensitivity and whatif analysis levels are identified for the stochastic cargo transport demand: an upper limit, a deterministic-equivalent value, and a lower limit. To enable such analysis to take place, SOS Voyager archives data of every cargo offer for as long time as it takes to identify the behavior pattern of cargo quantity and freight. In the light of this pattern along with the forecast of future events that might affect it, a probability distribution of cargo transport demand may now be built and maintained.

The net present value formula is well-known and can be found everywhere in the investment literature (take Evans and Marlow 1990 as one reference). However, the contribution made in the above-mentioned model is in the formulation of its objective function as it includes gross profit generated from integrated systems like SOS Voyager 
and SOS Allocator. SOS Voyager creates input voyage parameters needed by SOS Allocator, and then SOS Allocator generates the yearly gross profit based on the trade area allocated to new ships in fair competition with already existing ones. The contribution is also made by the calculation of three net present values based on three levels of the stochastic cargo transport demand, as described in the following section.

\section{Case study on ship Appraiser}

The purpose of this case is to show the application of the model mentioned in the first subsection and sensitivity and what-if analysis referred to in this subsection. Assume that the shipping company ESC owns five oil tankers, working in tramp shipping business. To prepare the operational plan for the year 2019, ESC decided to re-allocate the five ships to oil trade areas, based on the gross profit each ship could earn in each area. A sixth oil tanker named El Kosseir was added to the plan as ESC is considering the purchase of this ship. For this purpose, ESC tried to figure out different voyages for each ship, one on each trade area. Stochastic cargo transport demand (quantity and freight rate) was then anticipated for a most-likely voyage most presenting each trade area. Demand is classified in three classes: upper limit, deterministic-equivalent value, and lower limit. SOS Voyager was then run to calculate voyage gross profit for each ship, including the new ship, on each trade area, using sensitivity and what-if analysis to calculate the gross profit for each demand class. Voyages failed to earn any gross profit were discarded. SOS Allocator was then run to see, for each demand class, what ship best fits in which trade area, and the frequency of calls it best completes in this trade area. This process results in a yearly gross profit for each ship for each demand class. Gross profit results for El Kosseir are reported in Table 17, along with similar results for the years until 2028. Cash flow data other than gross profit is also reported in this table. El Kosseir investment data is reported in Table 18.

SOS passes data in Tables 17 and 18 to SOS Appraiser as to appraise the purchase of El Kosseir. It calculates, according to the model mentioned in the first subsection, the net present values corresponding to the cargo stochastic transport demand upper limit,

Table 17 Yearly gross profit and cash flow data of El Kosseir in the period 2019-2028

\begin{tabular}{lllll}
\hline Year & \multicolumn{2}{l}{ Yearly gross profit in US\$, based on stochastic cargo transport demand: } & $\begin{array}{l}\text { Other } \\
\text { yearly } \\
\text { cash } \\
\text { flow in } \\
\text { Upper limit }\end{array}$ & \multicolumn{1}{c}{ deterministic-equivalence } \\
\hline 2019 & $7,245,200$ & $6,825,300$ & $6,221,200$ & 1500,000 \\
2020 & $7,832,100$ & $7,120,000$ & $6,514,100$ & $1,750,000$ \\
2021 & $8,464,000$ & $7,870,000$ & $7,143,000$ & $1,900,000$ \\
2022 & $9,182,000$ & $8,560,000$ & $7,932,000$ & $2,100,000$ \\
2023 & $10,291,000$ & $9,330,000$ & $8,722,000$ & $2,400,000$ \\
2024 & 11,024000 & $10,200,000$ & $9,670,000$ & $2,700,000$ \\
2025 & $11,694,000$ & $10,970,000$ & $10,472,000$ & $3,050,000$ \\
2026 & $12,598,000$ & $11,880,000$ & $11,507,000$ & $3,450,000$ \\
2027 & $13,610,000$ & $12,740,000$ & $12,530,000$ & $3,850,000$ \\
2028 & $14,140,000$ & $13,535,000$ & $13,314,000$ & $4,160,000$ \\
\hline
\end{tabular}


Table 18 El Kosseir investment data

\begin{tabular}{ll}
\hline Investment data item & Value in US\$ \\
\hline Cost of investment in US\$ & $24,700,000$ \\
Risk-based rate of return in \% & 7 \\
Rate of economic inflation in \% & 5 \\
\hline
\end{tabular}

deterministic-equivalence, and lower limit as follows: $\$ 17,483,560, \$ 13,634,102$, and $\$ 10,558,826$, respectively. This result tells the ship owner that net present value is going to lie between the indicated lower and upper limits, and most likely it will be close to the indicated deterministic-equivalent value.

It takes SOS Appraiser a fraction of a second to process the model. Hardware used is Intel i3 PCs. Software used are MS Windows 7, MS Access 2007 (front end), MS SQL Server 2008 (back end), optimisation programs, and Microsoft Message Passing Interface (for parallel processing).

\section{Concluding statement}

This concluding statement is to bring about the contribution made in this paper; which is to announce a new policy to all systems which are sensitive to time. In tramp cargo transportation, as an example, the current policy is to select for each transport unit the cargo mix which contributes more to a gross-profit objective, assuming deterministic cargo transport demand. Since tramp cargo transportation system is sensitive to time, where time varies considerably from one alternative ship voyage to another, a new policy would consider this objective as less profitable than gross-profit-per-day objective, assuming both deterministic and stochastic cargo transport demand. Owners of tramp transportation systems should worry not only about gross profit they expect to earn but also about the time taken in earning this profit. To introduce this new policy, SOS; a suite of decision support systems, is developed to optimise tramp shipping operations using a stochastic gross-profit-per-day objective. This new objective has been introduced in SOS Voyager section by a model developed for 'optimisation of ship voyage' research area. The analysis given by this section demonstrates the case where the deterministic gross-profit objective is considerably less profitable for tramp shipping than that given by the stochastic gross-profit-per-day objective. Therefore, the following new management policy is set for any time-sensitive cargo transportation system:

a) Use gross profit per day objective, rather than gross profit only.

b) Consider deterministic and stochastic cargo transport demand, rather than deterministic demand only.

c) Apply optimisation methods and use sensitivity and what-if analysis to validate the optimal solution.

In other words, old management policy of using gross-profit objective is not advised any more, even if stochastic transport demand is absent. In case the 
probability distribution cannot be identified for cargo transport demand, sensitivity and what-if analysis of cargo quantity and freight can be used with the grossprofit-per-day objective.

The impact of the new policy on any logistics and supply chain system is that it maintains the shortest possible transportation time the transportation system can afford. Findings of this part of the research paper can easily be extended to transportation systems other than cargo ships; namely cargo airplanes, trucks, and trains.

In SOS allocation model, it was shown that the optimal gross profit generated for each ship in each trade area can be used by SOS to allocate ships' voyages to world cargo trade areas within a long-term planning period. One useful application of this allocation is to consider the frequency of calls allocated in each trade area as representing demand of services provided in this area and use this demand to assess the competitiveness of utilities in cargo trade areas. Ports are taken as an example for such utilities. The analysis given by the case study on port development demonstrates the case where an optimal trade area improvement is advised by SOS Voyager and SOS Allocator so that all calling frequencies in this area are serviced and ship layups are avoided, while maintaining maximum revenue of area ports. Sensitivity and what-if analysis is the SOS tool to reach this optimal trade area improvement. Findings of this part of the research paper can easily be extended to other ship types, other port services, other utilities; namely canals and straits.

Another useful application of SOS Allocator is that it calculates the gross profit of the new ship each year of its lifetime when it is added to old fleet units in the allocation plan. SOS Appraiser, as described in SOS Appraiser section, can then calculate three appraisal values, corresponding to three levels of stochastic cargo transport demand: an upper limit, deterministic-equivalence, and lower limit. The case study in this section calculates the three net present values for an oil tanker to be purchased for tramp shipping service and demonstrates how the deterministic-equivalent value represents the most likely value in a range of values bounded by lower and upper limits.

The contribution of this paper is not only in developing a decision support system using innovative models and methodologies for tramp shipping optimisation, but also in the integration it provides between these models and methodologies. The integration between SOS Voyager and SOS Allocator permits an exchange of parameters like voyage gross profit to SOS Allocator and advisable working trade areas to SOS Voyager. A next year planning budget is an important product which could be produced from this integration. Likewise, integration between SOS Allocator and SOS Appraiser permits calculation of gross profit of new ships and passing it to SOS Appraiser. SOS may be tried and manipulated by free download from SOS (2018). The site contains all SOS data, programs, and user manuals. SOS similar systems may be tailored for other means of cargo transport.

Future work is suggested to go further in adding more shipping elements and rules so that tramp shipping models become more realistic. Elements such as flexible cargo sizes, splitting of loads, and different ship speed, although they affect profitability if formulated within the models, they can be handled instead by sensitivity and what-if analysis, giving other elements the chance to be formulated. Stochastic and profit-per-day 
models need more attention. Cargo transport demand needs more study on the construction of probability distribution of the transport demand for main types of cargo. OR-Based Decision Support Systems are used to integrate OR models into database management systems. It is highly recommended to build such systems for shipping so that OR methodologies become transparent to ship owners while being supportive at the same time. Moreover, these systems have to interact with the ship owner in friendlier sensitivity and what-if analysis sessions. Because hardware speed represents the prime limitation of the algorithm adopted in this paper, faster computer hardware and communication equipment must be used to enable ship owners take their decisions in the right time. Ship owners, operators of utilities, and researchers are encouraged to meet somewhere to discuss problems of mutual concern. It is highly recommended that workshops are to be considered as the places where all should meet to discuss case studies like the ones mentioned in this research paper. It is the role of international conferences to arrange such workshops in different places worldwide. The future work on tramp shipping should result in an impact on the logistic system in which transportation by ship is part of. An example of this impact is given by this research paper when it shows that shortening ship voyage time, to the extent ship owners can afford, is caused by a stochastic gross-profit-per-day objective. Finally, stochastic gross-profit-per-day objective may be used in other time-sensitive production systems. Examples are crop charts in agriculture, customized production line in industry, product maintenance schedule in services, project plan in construction, and logistics network in trade. It may be used as well in fixed-time production systems, before time being fixed, to determine the optimal amounts of factors of production employed in a multiple-products multiple-systems investment plan. Examples are crop harvesting in agriculture, car manufacturing and assembly lines in industry, port cargo handling in services, road paving in construction, and market control measurements in trade.

\section{Appendix 1}

\section{SOS Voyager optimisation model}

In this model, it is assumed that each ship starts its voyage at home port (open event) and returns back to its home port (close event). In this model let:

$S=\left\{1,2,3, \ldots, s_{0}\right\}$ be the set of ships,

$P=\left\{1,2,3, \ldots, p_{0}\right\}$ be the set of ports of a working trade area,

$Q=\left\{1,2,3, \ldots, q_{0}\right\}$ be the set of cargoes available for transport between ports of this area. It is assumed that cargoes are compatible with the ship carrying them and can be mixed together on board the ship with ship stability maintained. Each cargo $r \in Q$ has a loading event and a discharging event,

$L=\left\{1,2,3, \ldots, l_{0}\right\}$ be a set of loading events, one for each cargo,

$D=\left\{1,2,3, \ldots, d_{0}\right\}$ be a set of discharging events, one for each cargo,

$F=\{f\}$ be a one-element set of open event $f$,

$G=\{g\}$ be a one-element set of close event $g$,

$E=L \cup D$ be the set of load and discharge events, combined,

$E_{f}=E \cup F$ be the set of open, load, and discharge events, combined,

$E_{g}=E \cup G$ be the set of load, discharge, and close events, combined, 
$E_{f g}=E_{f} \cup G$ be the set of open, load, discharge, and close events, combined.

$p_{i}$ be port $p \in P$ identified at event $i \in E_{f g}$,

$Z=\{1,2,3,4\}$ be an index representing two combined positions: 'pass or bypass Suez or Panama Canal' as alternative route position, and 'laden or ballast' as ship load position. Z element of ' 1 ' represents ship passing canal while in laden position, '2' represents ship bypassing canal while in laden position, ' 3 ' represents ship passing canal while in ballast position, and '4' represents ship bypassing canal while in ballast position.

$p_{i j z}^{k}$ be the gross profit earned by ship $k \in S$ on transport link $i j$ while in position $z \in Z$. Gross profit equals freight plus demurrage (based on reversible or irreversible calculation), minus cooling/heating cost of cargo $r \in Q$ at $i \in L$, minus handling cost of cargo $r \in Q$ at $i \in E$, minus dispatch (based on reversible or irreversible calculation), minus port dues of port $p \in P$ at $i \in E_{f}$, where $p_{i} \neq p_{j}$, and minus canal/strait dues and fuel consumption of main engine when sailing transport link $i j$ while in position $z \in Z$, where $p_{i} \neq p_{j}$

$T_{g}^{k}$ be voyage close day of ship $k \in S$,

$C_{g}^{k}$ be the cost of fuel consumption of auxiliary engine per day plus daily fixed cost of ship $k \in S$,

$C_{0}^{k}$ be voyage fixed cost of ship $k \in S$, not considered elsewhere,

$x_{i j z}^{k}$ be the problem decision variable. It equals 1 if ship $k \in S$ sails transport link $i j$ while it is in position $z \in Z$, and it equals zero otherwise. If $x_{i j z}^{k}=1$ and $i \in E$, cargo $r \in$ $Q$ is loaded on board ship $k$, where $i$ is its loading port, or discharged from the ship if $i$ is its discharging port. Likewise, if $x_{i j z}^{k}=1$ and $j \in E$, cargo $r \in Q$ is loaded on board ship $k$, where $j$ is its loading port, or discharged from the ship if $j$ is its discharging port, $y_{i}$ be another problem decision variable, alternative to $x_{i j z}^{k}$. It may equal 1 if $x_{i j z}^{k}=0$ for all ships sailing all transport links to pick up cargo $r \in Q$ at $i \in L$, and it equals zero otherwise. Cargo $r \in Q$ at $i \in L$ is transported by a chartered-in ship in case it equals 1 . For the chartered-in ship, let $P_{i}$ be its voyage gross profit, $t_{i}$ be its voyage time, $C_{i 0}$ be its voyage fixed cost, and $t_{i 0}$ be its voyage fixed time. Each one of these parameters is to have a value $\neq 0$ if the chartered-in ship is taken as an alternative and a value $=0$ otherwise,

It is required to maximise the sum of voyage gross profit per day for all ships, given by:

$$
G=\sum_{k \in S}\left(\sum_{i \in E f} \sum_{j \in E g} \sum_{z \in Z} p_{i j z}^{k} x_{i j z}^{k}-C_{g^{k}} T_{g}^{k}-C_{0}^{k}\right) / T_{g}^{k}+\sum_{i \in L}\left(P_{i} y_{i}-C_{i 0}\right) /\left(t_{i} y_{i}+t_{i 0}\right)
$$

\section{Subject to:}

\section{Flow constraints}

Using the above-mentioned denotations, the flow constraints can be formulated as follows:

-The flow constraints which restrict the flow of transport links for each ship originating from open event to only one link at most, given by: 


$$
\sum_{j \in E g} \sum_{z \in Z} x_{f j z}^{k} \leq 1, k \in S
$$

-Flow constraints which restrict the flow of transport links for each ship towards event $e \in E$ to be equal to the flow of transport links outward from this event, given by:

$$
\sum_{i \in E f} \sum_{z \in Z} x_{i e z}^{k}=\sum_{j \in E g} \sum_{z \in Z} x_{e j z}^{k}, e \in E, \text { and } k \in S,
$$

-Flow constraints which restrict the flow of transport links for each ship towards load event $l \in L$ of cargo $r \in Q$ to be equal to the flow of transport links towards discharging event $d \in D$ of same cargo, given by:

$$
\sum_{i \in E f} \sum_{z \in Z} x_{i l z}^{k}=\sum_{i \in E} \sum_{z \in Z} x_{i d z}^{k}, l \in L, d \in D, l \text { and } d \text { are of same cargo } r \in Q \text {, and } k \in S,
$$

-Flow constraints which prohibit the flow of transport link of each ship in two opposite directions, given by:

$$
\sum_{z \in Z} x_{i j z}^{k}+\sum_{z \in Z} x_{j i z}^{k} \leq 1, i, j \in E, \text { and } k \in S
$$

-Flow constraints which restrict the flow of transport links of all ships towards loading event $l \in L$ of cargo $r \in Q$ plus their alternative decision of acquiring a charter-in ship, to only one at most, given by:

$$
\sum_{k \in S} \sum_{i \in E f} \sum_{z \in Z} x_{i l z}^{k}+h_{l} y_{l} \leq 1, l \in L, h_{l}=1 \text { if } y_{l} \text { is taken as an alternative decision and } h_{l}=0 \text { otherwise. }
$$

\section{Capacity constraints}

Let:

$w_{i}$ be weight of cargo $r \in Q$ at event $i \in E$, in $\mathrm{mt}$,

$v_{i}$ be volume of cargo $r \in Q$ at event $i \in E$, in cum (if non-container),

$n_{i}$ be number of TEU of cargo $r \in Q$ at event $i \in E$ (if container),

$W_{i}^{k}$ be the remaining dwt capacity of ship $k \in S$ after load or discharge of cargo $r \in Q$ at event $i \in E$, in $\mathrm{mt}$,

$W_{0}^{k}$ be the min weight remaining on board ship $k \in S$ which keeps the ship in laden position,

$V_{i}^{k}$ be the remaining volume capacity of ship $k \in S$ after load or discharge of cargo $r \in Q$ at event $i \in E$, in cum (if non-container),

$N_{i}^{k}$ be the remaining TEU capacity of ship $k \in S$ after load or discharge of cargo $r \in Q$ at event $i \in E$ (if container),

$W^{k}$ be the dead weight capacity of ship $k \in S$,

$V^{k}$ be the volume capacity of ship $k \in S$ (if non-container),

$N^{k}$ be the TEU capacity of ship $k \in S$ (if container),

Using the above-mentioned denotations, the capacity constraints can be formulated as follows: 
-Load remaining weight constraints which restrict remaining weight on board each ship at end event $j \in E$ to be at least equal to remaining weight at start event $i \in L$ of any transport link minus weight of cargo $r \in Q$ at $i \in L$, given by:

$$
W_{j}^{k} \geq W_{i}^{k}-w_{i} \sum_{z \in Z} x_{i j z}^{k}, i \in L, j \in E, \text { and } k \in S, \text { where } \sum_{z \in Z} x_{i j z}^{k}=1,
$$

Constraints (7) can be re-written as follows:

$$
M\left(1-\sum_{z \in Z} x_{i j z}^{k}\right)+W_{j}^{k} \geq W_{i}^{k}-w_{i} \sum_{z \in Z^{x_{i j z}}}, i \in L, j \in E \text { and } k \in S,
$$

where $M$ is a big number. So $W_{j}^{k} \geq W_{i}^{k}-w_{i} \sum_{z \in Z} x_{i j z}^{k}$ will hold true only when $\sum_{z \in Z} x_{i j z}^{k}=1$.

-Load remaining volume constraints which restrict remaining volume on board each non-container ship at end event $j \in E$ to be at least equal to remaining volume at start event $i \in L$ of any transport link minus volume of cargo $r \in Q$ at event $i \in L$ given by:

$$
V_{j}^{k} \geq V_{i}^{k}-v_{i} \sum_{z \in Z} x_{i j z}^{k}, \quad i \in L, j \in E, \text { and } k \in S, \text { where } \sum_{z \in Z} x_{i j z}^{k}=1,
$$

-Load remaining TEU constraints which restrict remaining TEU on board each container ship at end event $j \in E$ to be at least equal to remaining TEU at start event $i \in L$ of any transport link minus TEU of cargo $r \in Q$ at event $i \in L$ given by:

$$
N_{j}^{k} \geq N_{i}^{k}-n_{i} \sum_{z \in Z^{\prime}} x_{i j z}^{k}, i \in L, j \in E, \text { and } k \in S, \text { where } \sum_{z \in Z^{x}} x_{i j z}^{k}=1,
$$

-Discharge remaining weight constraints which restrict remaining weight on board each ship at end event $j \in E$ to be at least equal to remaining weight at start event $i \in$ $D$ of any transport link plus weight of cargo $r \in Q$ at event $i \in D$, given by:

$$
W_{j}^{k} \geq W_{i}^{k}+w_{i} \sum_{z \in Z_{i j z}} x_{i j}^{k}, i \in D, j \in E, \text { and } k \in S, \text { where } \sum_{z \in Z^{\prime}} x_{i j z}^{k}=1,
$$

-Discharge remaining volume constraints which restrict remaining volume on board each non-container ship at end event $j \in E$ to be at least equal to remaining volume at start event $i \in D$ of any transport link plus volume of cargo $r \in Q$ at event $i \in D$, given by:

$$
V_{j}^{k} \geq V_{i}^{k}+v_{i} \sum_{z \in Z} x_{i j z}^{k}, i \in D, j \in E, \text { and } k \in S, \text { where } \sum_{z \in Z} x_{i j z}^{k}=1,
$$

-Discharge remaining TEU constraints which restrict remaining TEU on board each container ship at end event $j \in E$ to be at least equal to remaining TEU at start event $i \in D$ of any transport link plus TEU of cargo $r \in Q$ at event $i \in D$, given by:

$$
N_{j}^{k} \geq N_{i}^{k}+n_{i} \sum_{z \in Z^{\prime}} x_{i j z}^{k}, i \in D, j \in E, \text { and } k \in S, \text { where } \sum_{z \in Z^{\prime}} x_{i j z}^{k}=1,
$$

-Weight capacity constraints which restrict remaining weight on board each ship after discharge of all cargoes at end event $g \in G$ so that it does not exceed ship dwt capacity, given by: 


$$
W_{i}^{k} \geq W^{k}, i \in D, \text { and } k \in S, \text { where } \sum_{z=3,4} x_{i g z}^{k}=1, g \in G
$$

-Volume capacity constraints which restrict remaining volume on board each noncontainer ship after discharge of all cargoes at end event $g \in G$ so that it does not exceed ship volume capacity, given by:

$$
V_{i}^{k} \geq V^{k}, i \in D \text {, and } k \in S, \text { where } \sum_{z=3,4} x_{i g z}^{k}=1, g \in G,
$$

-TEU capacity constraints which restrict remaining TEU on board each container ship after discharge of all cargoes at end event $g \in G$ so that it does not exceed ship TEU capacity, given by:

$$
N_{i}^{k} \geq N^{k}, i \in D, \text { and } k \in S, \text { where } \sum_{z=3,4} x_{i g z}^{k}=1, g \in G,
$$

-Laden-or-ballast load position constraints which restricts ship load position to either laden or ballast. Ship is assumed to be in laden position on transport link $i j$ if $i \in L$, and is considered so if $i \in D$ and remaining weight on board the ship at this event is greater or equal to the min remaining weight $W_{0}^{k}$, which is given by:

$$
W_{i}^{k} \geq W_{0,}^{k}, i \in D, \text { and } k \in S, \text { where } \sum_{z=1,2} x_{i j z}^{k}=1, j \in E,
$$

\section{Time constraints}

Let:

$a_{i}$ be laycan open day of cargo $r \in Q$ at event $i \in E$,

$b_{i}$ be laycan close day of cargo $r \in Q$ at event $i \in E$,

$t_{i}^{k}$ be the number of days taken to handle cargo $r \in Q$ at event $i \in E$ by ship $k \in S$ plus waiting days at port $p \in P$ at event $i \in E$,

$t_{i j z}^{k}$ be the number of days taken to sail the transport link from event $i \in E_{f}$ to event $j \in E_{g}$ by ship $k \in S$ while it is in position $z \in Z$, plus waiting days at sea, where $p_{i} \neq p_{j}$,

$T_{i}^{k}$ be the arrival day of ship $k \in S$ at event $i \in E_{f g}$, assuming $T_{f}^{k}=0$,

$T_{0}^{k}$ be voyage fixed days of ship $k \in S$, not considered elsewhere,

$T_{s}^{k}$ be voyage slack days of ship $k \in S$, if it arrives earlier than $a_{r i}$, aggregated for all $r \in Q$ and $i \in E$,

$T^{k}$ be total allowable days of ship $k \in S$,

Using the above-mentioned denotations, the time constraints can be formulated as follows:

-Event arrival time constraints which restrict arrival day at end event $j \in E_{g}$ to be at least equal to arrival day at start event $i \in E_{f}$ of any transport link plus handling days of cargo $r \in Q$ at $i \in$ $E_{f}$ waiting days in port $p \in P$ at $i \in E_{f}$ sailing days on link $i j$, and waiting days at sea, given by:

$$
T_{j}^{k} \geq T_{i}^{k}+t_{i}+\sum_{z \in Z} t_{i j z}^{k} x_{i j z}^{k}, i \in E_{f}, j \in E_{g}, \text { and } k \in S, \text { where } t_{i f z}^{k}=0, \text { and } \sum_{z \in Z} x_{i j z}^{k}=1,
$$

-Event time precedence constraints which control arrival times so that arrival day at discharge event $d \in D$ succeeds arrival day at load event $l \in L$ of cargo $r \in Q$, given by: 
$T_{d}^{k} \geq T_{l}^{k}, l \in L, d \in D, l$ and $d$ are of same cargo $r \in Q$, and $k \in S$, where $\sum_{i \in E} \sum_{z \in Z} x_{i d z}^{k}=1$

-Time window constraints which restrict ship arrival day at event $j \in E$ so that it does not violate cargo laycan open and close days at this event, given by:

$$
\begin{aligned}
& T_{j}^{k} \geq a_{i}, j \in E, \text { and } k \in S, \text { where } \sum_{i \in E f} \sum_{z \in Z} x_{i j z}^{k}=1, \\
& T_{j}^{k} \leq b_{i}, j \in E, \text { and } k \in S, \text { where } \sum_{i \in E f} \sum_{z \in Z^{k}} k_{i j z}^{k}=1,
\end{aligned}
$$

-Closing time constraints which restrict final closing day for each ship so that it equals total cargo handling days and waiting days in port, sailing days and waiting days at sea, waiting days before cargo open day, and voyage fixed days, given by:

$$
\sum_{i \in E f} \sum_{j \in E g} \sum_{z \in Z}\left(t_{i}^{k}+t_{i j z}^{k}\right) x_{i j z}^{k}+T_{s}^{k}+T_{0}^{k}=T_{g}^{k}, k \in S,
$$

-Allowable closing time constraints which restrict closing day for each ship to a maximum allowable days, given by:

$$
T_{g}^{k} \leq T^{k}, g \in G, k \in S, \text { where } \sum_{z=3,4} x_{i g z}^{k}=1 \text { and } i \in D
$$

\section{Non-negativity and integrality constraints}

-Non-negativity constraints of continuous variables, given by:

$$
W_{i}^{k}, V_{i}^{k}, N_{i}^{k}, T_{i}^{k} \geq 0, i \in E_{g}, k \in S
$$

-integrality constraints of integer variables, given by:

$$
\begin{aligned}
& x_{i j z}^{k}=0,1, i \in E_{f}, j \in E_{g}, z \in Z, k \in S, \\
& \sum_{z \in Z} x_{i j z}^{k} \leq 1, i \in E_{f}, j \in E_{g}, k \in S, \\
& y_{i}=0,1, i \in L .
\end{aligned}
$$

The chance-constrained version of the above-mentioned model can be described using the following simple denotations, assuming one ship and one cargo. The transport demand of this cargo is unconfirmed, assumed to be random variable having a known probability distribution. The probability distribution is the marginal distribution of demand. Let:

$d$ be the deterministic cargo transport demand, expressed in quantity units,

$D$ be the random cargo transport demand, expressed in quantity units,

$P$ be the least probability ship owner stipulates to transport cargo within $D$,

$y$ be the quantity of cargo to be transported.

Transport demand constraint implied by the model is given by:

$$
y \leq d,
$$

In chance-constrained model this constraint reads: the probability of transporting cargo within demand; Prob. $\{y \leq D\}$, has to be greater or equal to $P$, as indicated by: 
Prob. $\{y \leq D\} \geq P$,

Constraint (27) is called 'chance-constraint', as being named by Charnes and Cooper (1959). If at $D=\underline{d}$ the descending cumulative probability of transport demand of cargo has a value just greater or equal to $P$, then (27) in this case implies:

$$
y \leq \underline{\mathrm{d}}
$$

Constraint (28) is the deterministic-equivalent constraint to (27). It is different from constraint (26). The difference is that $d$ in (26) is the quantity of cargo $r$ fixed demand, while $\underline{d}$ in (28) is a deterministic-equivalent quantity of cargo random demand, as described earlier. To illustrate, assume for discrete cargo demand $D$, Prob. $\{D<$ 5 units $\}=0.0$, Prob. $\{D=5$ units $\}=0.2$, Prob. $\{D=10$ units $\}=0.5$, Prob. $\{D=$ 15 units $\}=0.3$, and Prob. $\{D>15$ units $\}=0.0$. According to the additive rule of the probability theory, the demand descending cumulative probability distribution reads: Prob. $\{D \geq 5$ units $\}=0.2+0.5+0.3+0.0=1.0,0.8 \leq$ Prob. $\{D \geq 10$ units $\}<1.0$, and $0.3 \leq$ Prob. $\{D \geq 15$ units $\}<0.8$. Now suppose $P=0.9$. This value falls in second class, which implies a deterministic-equivalent demand value of 10 units (neither 5 nor 15 units), i.e. at $\underline{d}=10$.

As defined earlier, the chance-constrained model is exactly (1) to (25) after converting implied constraint (26) to (28). Use the same illustration mentioned above to convert quantities in Table 4 to deterministic-equivalent quantities as shown in Table 5.

The model is solved by the state-of-the-art Block-Angular Linear Ratio Programming algorithm (see El Noshokaty, 2014). In this algorithm, the problem mathematically takes a block-angular form, with a block of objective and constraints assigned to each ship. The model is transformed to a linear form and solved by a modified Mixed Continuous 0-1 Linear Programming algorithm. In this algorithm, a modified Branch and Bound technique of Land and Doig (1960) is used to solve the mixed continuous 0-1 linear program. At each node in the branch, the problem is decomposed by a modified Dantzig and Wolfe (1960) into sub-problems, one for each ship, and then solved by a modified Simplex method as indicated by the algorithm. The reason for formulating the model the way mentioned earlier is that it is amenable to the above-mentioned techniques and methods, which are highly efficient and reliable, even if the model has a very large number of variables and constraints.

\section{Appendix 2}

\section{SOS Allocator optimisation model}

In this model, let:

$L=\left\{1,2,3, \ldots, l_{0}\right\}$ be the set of shipping trade areas. A trade area describes a sea trade between ports in a given geographical place,

$S=\left\{1,2,3, \ldots, s_{0}\right\}$ be the set of ships of single ship type, or multiple ship types if more than one type competes in carrying same cargo,

$t_{i j}$ be the number of days spent in a most-likely-voyage by ship $i \in S$ in trade area $j \in$ $L$,

$w_{i}$ be the deadweight of ship $i \in S$, in metric ton (mt),

$C_{i}$ be the fixed cost per day of ship $i \in S$,

$D_{i}$ be the yearly working days available for ship $i \in S$, in number of days, 
$Q_{j}$ be the yearly max quantity available as cargo demand (including contracted cargoes) on trade area $j \in L$, in mt,

$q_{j}$ be the yearly min quantity available as contracted cargoes on trade area $j \in L$, in $\mathrm{mt}$,

$g_{i j}$ be the most-likely-voyage gross profit ship $i \in S$ earns on trade area $j \in L$ (provided by SOS Voyager),

$x_{i j}$ and $y_{i}$ be the problem decision variables; $x_{i j}$ be the frequency of calls to be completed by ship $i \in S$ on trade area $j \in L$ per year, and $y_{i}$ be the lay-up days of ship $i \in S$ per year.

It is required to find the values of $x_{i j}$ and $y_{i}$, where $i \in S$ and $j \in L$, which maximise total gross profit, given by:

$$
G=\sum_{i \in S} \sum_{j \in L} g_{i j} x_{i j}-\sum_{i \in S} C_{i} y_{i}
$$

Subject to the following constraints:

-Time constraints put by ship yearly working days on total days spent by each ship on all trade areas, given by:

$$
\sum_{j \in L} t_{i j} x_{i j}+y_{i}=D_{i}, i \in S
$$

- Quantity constraints put on total weight of cargoes carried by all ships in each trade area each year, given by:

$$
q_{j} \leq \sum_{i \in S} w_{i} x_{i j} \leq Q_{j}, j \in L
$$

If ships working on trade area $j \in L$ have $w_{j}$ uniform deadweight, then both sides of constraints (31) can be divided by $w_{j}$, and these constraints can then be re-written as:

$$
f_{j} \leq \sum_{i \in S} x_{i j} \leq F_{j}, j \in L,
$$

Where $F_{j}=Q_{j} / w_{j}$ and $f_{j}=q_{j} / w_{j}$ are the maximum and minimum values, respectively, the frequency of calls: $\sum_{i \in S} x_{i j}$ can take on trade area $j \in L$. If ships working on trade area $j \in L$ have more than one uniform deadweight, this trade area may be divided into multiple virtual trade areas, one for each uniform deadweight.

-Non-negativity and integrality constraints, given by:

$$
x_{i j} \geq 0, i \in S \text {, and } j \in L \text {, where } x_{i j} \text { is integer, and } y_{i} \geq 0, i \in S
$$

The model is solved by the well-known Integer Continuous Linear Programming algorithm.

\section{Appendix 3}

\section{SOS Appraiser model}

In this model, let:

$N_{0}=\left\{1,2,3, \ldots, n_{0}\right\}$ be the common set of years of any new ship life time,

$S=\left\{1,2,3, \ldots, s_{0}\right\}$ be the set of new ships,

$J=\{1,2,3\}$ be the stochastic cargo transport demand index, where $J=1$ if net present value is based on upper limit, $J=2$ if based on deterministic-equivalence, and $J=3$ if based on lower limit of the stochastic cargo transport demand. 


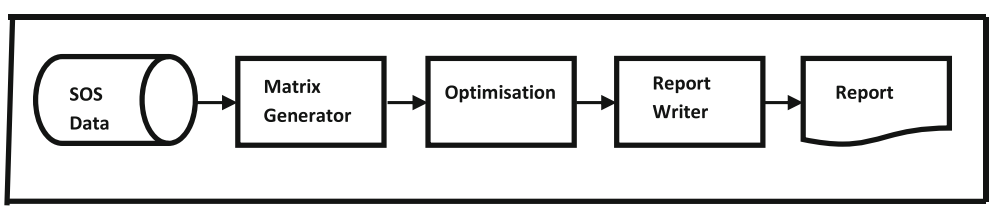

Fig. 1 SOS Voyager system flow chart

$g^{j}{ }_{i n}$ be the gross profit ship $i \in S$ earns in year $n \in N_{0}$ based on $j \in J$ cargo transport demand index, where ship depreciation is not included. This parameter is provided by both SOS Voyager and SOS Allocator,

$c_{i n}$ be the net cash of ship $i \in S$ flows in year $n \in N_{0}$. Cash flow items, other than that related to gross profit, include loan installments, loan interest, tax, tax relief, and grants,

$c_{i 0}$ be the cost of investment of ship $i \in S$,

$r_{i}$ be the risk-based rate of return on investment for ship $i \in S$,

$e$ be the rate of economic inflation.

The net present value; $V_{i}^{j}$, is equal to the discounted net cash flow of ship $i \in S$ based on $j \in J$ cargo transport demand index, as shown by:

$$
\begin{aligned}
V_{i}^{j} & =\sum_{n \in N_{0}} G_{i n}^{j} R_{i}^{-n}-c_{i 0}, i \in S, j \in J, \text { where : } \\
G_{i n}^{j} & =g_{i n}^{j}-c_{i n}, \text { and } R_{i}=1+r_{i}+e
\end{aligned}
$$

\section{Appendix 4}

\section{Description of SOS voyager tasks behind the output of Table 6}

Figure 1 shows SOS Voyager system flow chart. It shows the flow of data through the SOS Voyager sub-systems: Matrix Generator, Optimisation, and Report Writer. The tasks behind the output of Table 6 cut across all the sub-systems.

The first task, performed in Matrix Generator, is to access data of each ship recorded in SOS Data database, which is displayed in Tables 1 to 5 . The second task is to convert this data into model parameters as shown in Appendix 1, after excluding infeasible parameters. In doing this, SOS Voyager must find whether sensitivity or what-if analysis is required. In our case, sensitivity analysis is required for ship speed, where speed data and fuel consumption data are contained in three levels, as shown in Table 1. So, model parameters affected by speed change should be calculated for each speed level. The third task is to place parameters corresponding to each speed level where they belong in a simplex matrix of coefficient for each ship and for a master matrix, where matrix columns represent variables and rows represents constraints. The master matrix controls processing of all ships. The fourth task, performed in Optimisation, is to distribute processing of the model among cores of multiple PCs, one core for each matrix. The fifth task is to perform optimisation three times, one for each sensitivity level. If the reader recalls the methodology mentioned at the end of Appendix 1, which is needed to process the model each time, he can imagine how enormous task number five is. The sixth task, performed in Report Writer, is to convert matrix coefficients of the optimal solution into sensitivity analysis report (Table 6), which contains optimal cargo mix, route, and gross profit per day for each ship for each sensitivity level. The seventh 
task is to revert to 'Tramp Shipping Optimisation Main Menu', in case the user needs, upon reviewing the sensitivity analysis report, to validate the model by further performing additional what-if analysis sessions. In each session, the above-mentioned tasks are repeated, but now for only one analysis level. Sensitivity and what-if analysis can be performed not only for ship speed and fuel consumption, but also for cargo freight rate and quantity, and cargo handling rate and charges.

Competing interests

The authors declare that they have no competing interests.

\section{Publisher's note}

Springer Nature remains neutral with regard to jurisdictional claims in published maps and institutional affiliations.

Received: 22 July 2016 Accepted: 20 June 2017

Published online: 10 July 2017

\section{References}

Appelgren L (1969) A column generation algorithm for a ship scheduling problem. Transp Sci 3(1):53-68 Appelgren L (1971) Integer Programming Methods for Vessel Scheduling Problem. Transp Sci 5(1):64-78 Bakkehaug R, Rakke J, Fagerholt K (2016) An adaptive large neighborhood search heuristic for fleet Deployment with voyage separation requirements. Transportation Research Part C: Emerging Technology 70:129-114

Bauch D, Brown G, Ronen D (1998) Scheduling short-term Marine transport of bulk products. Marit Policy Manag 25(4):335-348 Bremer W, Perakis A (1992a) An operational tanker scheduling optimisation system: back ground, current practice and model formulation. Marit Policy Manag 19(3):177-187

Bremer W, Perakis A (1992b) An operational tanker scheduling optimisation system: model implementation, results and possible extensions. Marit Policy Manag 19(3):189-199

Brown G, Graves G, Ronen D (1987) Scheduling Ocean transportation of crude oil. Manag Sci 33(3):335

Charnes A, Cooper W (1959) Chance-constrained programming. Manag Sci 6(3):73-79

Christiansen M, Fagerholt K (2014) Ship routing and scheduling in industrial and tramp shipping. Accepted for publication in vehicle routing: problems, methods, and applications 2nd (eds. Toth and Vigo), SIAM

Christiansen M, Fagerholt K, Ronen D (2004) Ship routing and scheduling: status and perspectives. Transp Sci 38(1):1-18

Christiansen M, Fagerholt K, Nygreen B, Ronen D (2007) Marine transportation. In: Bernhart C, Laporte G (eds) Handbooks in operations research and management science: transportation. Elsevier, Amsterdam, pp 189-284

Christiansen M, Fagerholt K, Nygreen B, Ronen D (2013) Ship routing and scheduling in the new millennium. Eur J Oper Res 228(1):467-483

Dantzig G, Wolfe P (1960) Decomposition principle for linear programs. Oper Res 8(1):101-111

El Noshokaty S (1988) Optimum ship selection of ports, route, and cargoes, A PhD thesis submitted to the Institute of Shipping. University of Wales, Cardiff

El Noshokaty S (2013) Shipping optimisation systems (SOS): liner optimisation perspective. Int J Ship Transp Log 5(3):237-256

El Noshokaty S (2014) Block-angular linear Ratio Programmes. Int J Oper Res 19(3):338-357

Evans J, Marlow P (1990) Quantitative methods in maritime economics, 2nd edn. Fairplay Publications, UK

Fagerholt K (2001) Ship scheduling with soft time Windows: an optimisation based approach. Eur J Oper Res 131(3):559-571

Fagerholt K (2004) A computer-based decision support system for vessel fleet scheduling - experience and future research. Decis Support Syst 37(1):35-47

Fagerholt K, Lindstad H (2000) Optimal policies for maintaining a supply Service in the Norwegian sea. Omega 28(3):269-275

Fagerholt K, Christiansen M, Hvattum L, Johnsen T, Vabo T (2010) A decision support methodology for strategic planning in maritime transportation. Omega 38(6):465-474

Fields C. and Shingles L. (2016) Trade in a sea of uncertainty: Seaborne trade remains vulnerable to a throng of downside risks, according to the latest UNCTAD report, Baltic Briefing, main Baltic website (Nov. 7, 2016)

Hemmati A, Hvattum L, Norstad I, Fagerholt K (2014) Benchmark suite for industrial and tramp ship routing and scheduling problems. Infor Sys Oper Res 52(1):28-38

Jaramillo D, Perakis A (1991a) Fleet Deployment optimisation for liner shipping - part 2: implementation and results. Marit Policy Manag 18(4):235-262

Jaramillo D, Perakis A (1991b) Fleet Deployment optimisation for liner shipping - part 1: background, problem formulation and solution approaches. Marit Policy Manag 18(3):183-200

Kim S, Loe K (1997) An optimisation-based decision support system for ship scheduling. Comput Ind Eng 33(3-4):689-692

Laake J, Zhang A (2013) An optimisation model for strategic fleet planning in tramp shipping, 2013 joint NZSA + ORSNZ conference, pp 1-18

Land A, Doing A (1960) An automatic method of solving discrete programming problems. Econometrica 28(3): 497-520

Lin D, Liu H (2011) Combined ship allocation, routing and freight assignment in tramp shipping. Transp Res E 47:414-431

Osman M.S.A., Hassan S., and Roshdy M. (1993) Generalized Model for Solving the Tramp Ship Scheduling Problem with Multi-Commodity', Modeling, Measurement \& Control, 4, Association for Modeling and Simulation in Enterprises (AMSE) Press, France. 7;1:31-42

Powell B, Perakis A (1997) Fleet Deployment Optimisation for Liner Shipping: An Integer Programming Model. Marit Policy Manag 24(2):183-192

Shipping Optimisation Systems (SOS) (2018).www.elesteshary.com/Products_SOS.html 
Tsilingiris P (2005) A multi-stage decision-support methodology for the optimisation-based liner-network design, A diploma thesis. School of Naval Architecture and Marine Engineering of the National Technical University of Athens, Athens

Vilhelmsen C, Larsen J, Lusby RM (2013) The tank allocation problem in bulk shipping. DTU Management Engineering, Denmark

Vilhelmsen C, Larsen J, Lusby RM (2015) Tramp ship routing and scheduling - models, methods and opportunities. DTU Management Engineering, Denmark

Vilhelmsen C, Larsen J, Lusby RM (2017) Tramp ship routing and scheduling with voyage separation requirements. OR Spectr:1-31. doi:10.1007/s00291-017-0480-4

\section{Submit your manuscript to a SpringerOpen ${ }^{\circ}$ journal and benefit from:}

- Convenient online submission

- Rigorous peer review

- Open access: articles freely available online

- High visibility within the field

- Retaining the copyright to your article

Submit your next manuscript at $\gg$ springeropen.com 